\title{
ACTUACIONES ARQUEOLÓGICAS DE URGENCIA EN EL EXTREMO MERIDIONAL DEL CASCO HISTÓRICO DE CÓRDOBA: EL SECTOR DE LA RIBERA
}

\author{
José Antonio MORENA LÓPEZ \\ Daniel BOTELLA ORTEGA
}

\section{Resumen}

Se ofrecen los resultados obtenidos en varias intervenciones arqueológicas de urgencia practicadas en un sector hasta ahora muy poco conocido de Colonia Patricia, en concreto, el comprendido entre la Cruz del Rastro y la Puerta del Puente. Dichos resultados permiten acercarnos al estudio de las características de ese sector urbano en lo que a su trama viaria se refiere, al tiempo que sugieren nuevos planteamientos respecto del trazado tan problemático de la muralla meridional. Así mismo, ponen de manifiesto la importancia que tuvo la zona, durante la época romana, desde el punto de vista económico y comercial, habiéndose detectado actividades de carácter metalúrgico y otras relacionadas con una instalación oleícola.

\begin{abstract}
The results obtained in some urgent archaeological intervention are presented. They were performed in a sector of Colonia Patricia, up to now very little known, to be exact, between Cruz del Rastro and Puerta del Puente. These results allow to approach the characteristics study of that urban sector regarding its road network. At the same time these results suggest new approaches with regard to the layout of the southern wall, so problematic. Also, they reveal the significance that the zone had, during the Roman age, from the economic and commercial point of view, getting information about metallurgic activities and others related with an olive-oil installation.
\end{abstract}

\section{Síntesis del registro arqueológico de solares excavados}

Aunque, vamos a mencionar los cuatro solares hasta ahora excavados en este tramo de la Ribera comprendido entre la Cruz del Rastro y la Puerta del Puente, nos centraremos básicamente en los tres primeros, cuya dirección y autorización nos fue 
encomendada por la Dirección General de Bienes Culturales de la Junta de Andalucía, concretando nuestro estudio en los restos documentados de época romana.

El solar sito en C/ Caño Quebrado, 3 esquina Ronda de Isasa fue excavado por José A. Morena en 1995 (Fig. $1 \mathrm{n}^{\circ} 1$ ) y de él ya se ha publicado un avance (MORENA, 1997); el localizado en Ronda de Isasa, 4 por Daniel Botella y José A. Morena en 1997 (Fig. $1 \mathrm{n}^{\circ}$ 2) y el ubicado en C/ Poeta Ricardo Molina esquina Ronda de Isasa por José A. Morena durante el mismo año de 1997 (Fig. $1 \mathrm{n}^{\circ}$ 3). En todos estos solares no se pudo actuar a lo largo de una franja paralela a la actual fachada a Ronda de Isasa, de unos $4 \mathrm{~m}$. de anchura, pues en lo que se refiere a ordenanzas de edificación, el Plan Especial del Río establecía un retranqueo obligado de la nueva alineación de fachada a Ronda de Isasa, según una paralela a la cara interior del antepecho del muro del Río de unos $20 \mathrm{~m}$.

El proceso de excavación se basó en la documentación de las distintas unidades estratigráficas (UU.EE.), según los principios básicos establecidos por el método Harris. De estos tres solares excavados por nosotros, fueron los de C/ Caño Quebrado, 3 y Ronda de Isasa, 4 los que más datos proporcionaron, y aún así éste último no deparó los resultados que inicialmente se esperaban pues el depósito estratigráfico de la mitad oriental del solar había sido arrasado a comienzos de la presente centuria, hecho que también se advirtió en el solar de la C/ Poeta Ricardo Molina esquina a Ronda de Isasa.

Por su parte, la excavación del solar situado en C/Amparo, 5-7 fue realizada por Dña. Laura Aparicio en 1993 y aunque dicha intervención se presentaba muy interesante dado que era la primera vez que se actuaba en la zona por la que supuestamente discurría la muralla meridional de la ciudad, sus resultados aún no han sido publicados. Al parecer se localizó parte de un muro, de orientación E-O. paralelo a la actual línea de fachada, de unos $7 \mathrm{~m}$. de longitud y una anchura máxima de $2.50 \mathrm{~m}$. Junto a este muro, que fue interpretado como parte del lienzo meridional de la muralla romana de la ciudad, se disponía parte de una calzada de unos $8 \mathrm{~m}$. de longitud y unos $3 \mathrm{~m}$. de ancho, cuyo pavimentó estaba formado por grandes losas de piedra de mina y alguna pudinga, siendo posible que se tratara de elementos reutilizados de una calzada anterior. Perpendicular a la supuesta muralla y calzada se localizaron una serie de grandes sillares formando dos alineaciones paralelas y entre ellas un pavimento similar al descrito y debajo una gran cloaca construida con sillares de caliza y con cubierta a dos aguas, correspondiente a un kardo.

Desde luego, uno los hallazgos más sobresalientes que deparó la excavación fue una pieza escultórica de mármol correspondiente a una copia romana de un modelo helenístico, a saber, la Venerem lavantem sese, que Plinio atribuye a Doidalsas de 
Bitinia, fechada hacia el 250 a.C. Esta copia de Afrodita agachada ha sido fechada en época antoniniana, sin mayor precisión, y su ubicación originaria puesta en relación con la decoración de un ninfeo o unas termas (APARICIO, 1994: 187-188).

\subsection{C/ Caño Quebrado, 3}

Se procedió a la excavación de cuatro cortes distribuidos por todo el solar, si bien, de los $627.50 \mathrm{~m}^{2}$ de superficie que éste tenía no pudo intervenirse en una franja de 4 m. de anchura, paralela a la actual Ronda de Isasa $\left(140 \mathrm{~m}^{2}\right)$, sobre la base de lo estipulado en el Plan Especial del Río. Las referencias altimétricas de la excavación están referidas a la cota actual del pavimento de Ronda de Isasa (97.08 m.s.n.m.).

El Corte 1, cuyas dimensiones fueron de $6 \times 4 \mathrm{~m}$., se planteó en el sector SE. del solar en el lugar más próximo posible al límite de los $4 \mathrm{~m}$. de retranqueo obligado por el Plan Especial del Río. El objeto era ajustarse lo máximo a la línea de fachada actual con la Ribera, donde se preveía la aparición de la antigua muralla defensiva de la ciudad. Las estructuras documentadas apoyaban directamente sobre el nivel geológico consistente en arena fina. Estas estructuras, situadas a similar cota, correspondían a cimentaciones realizadas a base de cantos rodados y alguna que otra piedra caliza, trabados con lima y arena, dispuestos en hiladas más o menos regulares como pudo verse en los muros de las UU.EE. 18 y 22.

Otra cimentación, que probablemente formó parte de la misma estancia junto con las anteriores, es la U.E. 22, construida sólo con piedras calizas sin escuadrar trabadas con lima y arena. Es posible que sobre éstas cimentaciones se alzaran muros de sillares como los que constituían la U.E. 16 colocados directamente sobre la U.E. 22. Este muro se fabricó con grandes sillares de caliza, bien escuadrados y asentados en seco, conservándose junto al vértice SE. del corte hasta tres hiladas de sillares en altura. No se documentó ningún pavimento asociado a la posible estancia delimitada por estos muros y cimentaciones. Sobre la base del material cerámico recogido en la U.E. 17, estas estructuras pudieron fecharse en época augustea.

Se localizaron varias ánforas olearias, habiéndose observado la destrucción parcial del muro U.E. 16 pues algunos de los sillares se habían roto para colocar dichos envases (Lám. I). Otro de estos grandes contenedores de aceite se había situado justo encima de la cimentación U.E. 20. (curiosamente todas las ánforas estaban en posición vertical y partidas o seccionadas por la mitad faltándoles la parte superior).

En el Corte 2, de 6x4 m., tampoco se detectaron estructuras de época republicana. Los restos constructivos más antiguos documentados correspondían a parte de un pavimento realizado en opus signinum con un espesor de unos $10 \mathrm{~cm}$. Este pavimento, que buzaba claramente de N-S., presentaba una potente cimentación formada por cuatro hiladas de cantos rodados y algunas piedras calizas trabadas con lima y arena, asentada 
directamente la hilada inferior sobre el nivel geológico estéril. Aunque la superficie del pavimento excavada era muy pequeña, sabemos que ésta era mayor y se encontraba sobre el nivel de cantos. No se excavó ningún muro de cerramiento de este suelo, pero en el extremo $\mathrm{O}$. se apreciaba el arranque de la típica media caña que suele acompañar a estos pavimentos de opus signinum de clara funcionalidad hidráulica.

Asociados a este suelo, aunque alterados por fases constructivas posteriores, se hallaron un gran sillar de caliza y un fuste de mármol blanco con vetas verdes. El sillar quedaba embutido en el perfil E., bajo el muro califal U.E. 10, de modo que su longitud total no pudo determinarse, siendo lo visible de $0.80 \times 0.50 \times 045 \mathrm{~m}$. El otro elemento correspondía a un fuste de columna reaprovechado, habiéndose efectuado en su parte superior una mortaja en forma de cola de milano mientras que el extremo inferior se había preparado mediante piqueteado similar al que se observa en la mortaja. Sus dimensiones son: $0.98 \mathrm{~m}$. de longitud y $0.22 \mathrm{~m}$. de diámetro; por su parte, el rebaje del fuste tiene una altura de $18 \mathrm{~cm}$. y una profundidad de $15 \mathrm{~cm}$., la anchura de la parte superior es de $13 \mathrm{~cm}$. y de la inferior de $9 \mathrm{~cm}$. Se localizó otro fragmento de fuste columna, de similares dimensiones pero de mármol blanco con vetas rojas con idéntico piqueteado en ambos extremos.

En el Corte 3, cuyas dimensiones fueron de $6 \times 3 \mathrm{~m}$., se recogió mayor cantidad de cerámica de barniz negro campaniense y también cerámica pintada de tradición ibérica, pero junto con materiales cerámicos de época imperial, no habiéndose documentado estructura alguna de época republicana. Las primeras estructuras exhumadas correspondían a dos muros de técnica edilicia diferente, uno a base de cantos rodados trabados con lima y arena (U.E. 23) y otro, de mayores proporciones, (U.E. 21), en el que destacaba la presencia de una gran losa de piedra de mina correspondiente a una quicialera de puerta que fue reaprovechada al construir dicho muro. Junto a estos muros se localizó in situ un ánfora olearia Dressel 20 (Fig. 5, Lám. III).

Sin duda, lo más interesante que proporcionó este corte fue la documentación de una calle romana, concretamente un kardo, con dirección NO-SE. El pavimento (U.E. 22), del que apenas se conservaban unas cuantas losas, estaba formado por grandes losas de pudinga acuñadas con ripios y otras piedras de similar dureza, con un grosor de unos $30 \mathrm{~cm}$. La cota de este pavimento era de $95.5 \mathrm{~m} . \mathrm{s} . \mathrm{n} . \mathrm{m}$. Bajo él se excavó un paquete de unos $0.70 \mathrm{~m}$. (UU.EE. 27 y 28) con abundante material cerámico: barniz negro campaniense, algunos fragmentos de ánforas itálicas, Dressel 7/11, 20, paredes finas, tapaderas de ánforas, barniz rojo julio-claudio, distintos tipos de TSI y TSG, etc. A continuación se halló, como era de esperar, la correspondiente cloaca (U.E. 29), con cubierta adintelada a base de losas de arenisca de grandes dimensiones, con una longitud de $1.50 \mathrm{~m}$., una anchura entre $0.80-1 \mathrm{~m}$. y un grosor de $0.25 \mathrm{~m}$. La caja de la cloaca era de grandes dimensiones (Lám. II), algo lógico por otra parte, tenien- 
do en cuenta que nos encontramos en el tramo final de la calle, muy próximo ya al río, donde el caudal de agua, tanto residuales como de lluvia, debía ser bastante elevado; su sección era ligeramente rectangular, algo más alta que ancha, (Fig. 3, A), siendo el ancho máximo de la caja de $0.50 \mathrm{~m}$. y su luz de $0.80 \mathrm{~m}$. La cota de la base es de 94 m.s.n.m. Sobre la base del material cerámico, la cronología de esta calle y del resto de las estructuras pudo fijarse en época augustea.

En cuanto al Corte 4 ( $5 \times 3 \mathrm{~m}$.), decir que el nivel de ocupación más antiguo lo definía la U.E. 14 fechada a mediados del s. I d.C. por la presencia de TSI y TSG, así como de marmorata. También se hallaron en esta unidad fragmentos de ánforas olearias, tapaderas de esas ánforas, cerámica de paredes finas y restos de estuco pintado en rojo. Las estructuras documentadas correspondían a una cimentación, excavada directamente sobre el nivel geológico, orientada de N-S, (U.E. 15) y realizada con pequeñas piedras irregulares dispuestas en cuatro hiladas irregulares, trabadas con arena, así como un posible pavimento de cantos rodados, asociado a dicha cimentación (U.E. 13). El material cerámico recogido en la U.E. 3 que cubría ambas construcciones confirma su uso durante el s. II d.C., sobre todo, por diferentes fragmentos de TSH y varias formas de cerámica africana de cocina (Fig. $6 \mathrm{n}^{\circ} 2$ y 3); también se hallaron sobre el pavimento dos piezas completas de cerámica común (Fig. $6 \mathrm{n}^{\circ} 1$ y 4 ).

\subsection{Ronda de Isasa, 4}

En este solar se abrieron seis cortes siendo la superficie total excavada de $231 \mathrm{~m}^{2}$ y las dimensiones de cada corte las siguientes: Corte 1: $8 \times 5 \mathrm{~m}$., con una ampliación de $3 \times 2 \mathrm{~m}$. Corte 2: $5 \times 4 \mathrm{~m}$. Corte 3: $5 \times 4 \mathrm{~m}$. Corte 4: $8 \times 5 \mathrm{~m}$. Corte 5: $8 \times 5 \mathrm{~m}$. Corte 6: $8 \times 5 \mathrm{~m}$. con dos ampliaciones, una de $4 \times 2 \mathrm{~m}$. y otra de $2 \times 4 \mathrm{~m}$. Además se procedió a la limpieza del talud norte del tacón macizo ubicado en el extremo oriental del colar con el objeto de documentar, en la medida de los posible, diversas estructuras existentes en esta zona y establecer su conexión con las detectadas en el Corte 6. Para las referencias altimétricas de la excavación nos basamos en la cota actual del acerado N. de Ronda de Isasa, justo enfrente de la C/ Poeta Ricardo Molina (96.32 m.s.n.m.).

La zona afectada por el proyecto de obra se componía de dos parcelas que tenían la siguiente superficie: la parcela $\mathrm{n}^{\circ} 1660.84 \mathrm{~m}^{2}$ y la $\mathrm{n}^{\circ} 21.059 .31 \mathrm{~m}^{2}$, con un total de $1.720 .15 \mathrm{~m}^{2}$. Pero como ya vimos, el Plan Especial del Río establecía un retranqueo que en este caso y dada la longitud de la fachada afectada, la pérdida de superficie fue sustancial para las referidas parcelas. La parcela $\mathrm{n}^{\circ} 1$ perdió $116.01 \mathrm{~m}^{2}$ y la $\mathrm{n}^{\circ} 2$ $196.19 \mathrm{~m}^{2}$, con un total de superficie perdida de $312.20 \mathrm{~m}^{2}$, es decir, el $18.15 \%$ del total., resultando una superficie final de $1.407 .95 \mathrm{~m}^{2}$ que fue la afectada por los trabajos de excavación arqueológica. Veamos a continuación lo que deparó el registro 
arqueológico en aquellos cortes con restos de época romana (Corte 1, 3 y talud N. del tacón oriental).

En el Corte 1 no se excavó ninguna estructura de época republicana y la presencia de material cerámico asignable a ese período (campanienses, ánforas itálicas y cerámicas pintadas de tradición indígena) recogido en algunas unidades estratigráficas no fue razón para determinar una ocupación del lugar en dicho momento histórico, pues la cronología de dichas unidades vino determinada por la aparición de otras cerámicas más recientes.

Las primeras estructuras levantadas en el corte que nos ocupa correspondían a las representadas por las UU.EE. $38,41,45$ y 50 , pues aunque no fue posible establecer una cronología concreta ante la ausencia de material arqueológico, es muy probable que dataran de época augustea. Las dos primeras, con cotas semejantes, consistían en estructuras fabricadas con cantos rodados trabados con tierra y arena, asentadas directamente sobre el terreno geológico que debieron servir de cimentación. La U.E. 38 presentaba una forma semicircular, adosada al perfil E., mientras que la U.E. 41 mostraba una clara orientación E-O. penetrando en el perfil $O$.

Por su parte, las estructuras correspondientes a las UU.EE. 45 y 50 estaban realizadas con materiales diferentes, en concreto, con losas y sillares de arenisca; las primeras empleadas en la cloaca U.E. 50 (en la base, paredes y cubierta), eran de grandes proporciones llegando a alcanzar algunas casi los $2 \mathrm{~m}$. de longitud (Láms. III-IV). Se trata, sin duda, de la estructura más interesante documentada en este Corte 1, porque supone la existencia en el lugar de una nueva calle de la que hasta ahora no se tenía constancia. La orientación de la cloaca (y de la calle) es NO-SE. y la diferencia de cotas evidenciaba algo lógico cual es la inclinación hacia el río para facilitar el drenaje y la evacuación tanto de las aguas de lluvia como de los vertidos residuales de las casas. La cota de la base de la cloaca era de 94.5 m.s.n.m. La cubierta original era a dos aguas y probablemente discurría adosada al muro E. de delimitación del kardo que, sin duda, existía sobre ella. Ese muro, correspondiente a la U.E. 45, estaba construido con grandes sillares de arenisca asentados en seco, y presentaba una orientación idéntica a la cloaca; no disponía de ningún tipo de cimentación, sino que la hilada inferior estaba colocada directamente sobre el terreno geológico. No pudimos documentar el pavimento de la calle, que debió de ser alterado cuando se procedió a la construcción de la estructura conformada por las UU.EE. 29 y 33. Sin embargo, parte de ese pavimento se halló en la U.E. 36 donde había tres losas de un conglomerado tipo pudinga, en posición secundaria, una de las cuales presentaba un rebaje central producido por el continuo tránsito de carruajes.

El resto de èstructuras romanas de este corte está identificado en las UU.EE. 29 y 33 que corresponden a una misma edificación construida con sillares y losas de arenisca, 
asentadas en seco y con ripios y lajas de piedra entre ellos para su mejor encaje. Al igual que el muro U.E. 45 no disponían de cimentación, de modo que los sillares de la hilada inferior estaban en contacto directo con el terreno geológico. Nos encontramos ante dos muros que no formaban exactamente un ángulo de $90^{\circ}$ sino que resultaba algo más abierto. El muro U.E. 33 presentaba una orientación N-S. aunque no iba paralelo al muro U.E. 45, mientras que la U.E. 29 estaba orientada de E-O.

Lo más significativo de estas unidades radicaba en que su construcción, que pudo fijarse a fines del s. III d.C. o comienzos del s. IV d.C. por la presencia de cerámicas africanas tipo $\mathrm{C}$ de la forma Hayes 50, supuso la amortización del kardo (en este momento debió formarse la U.E. 36 donde estaban las losas de pudinga dispuestas en posición secundaria), y procediéndose a la demolición parcial de la cloaca. En efecto, todo el lateral oriental de la caja y la cubierta fueron destruidos al levantarse el muro U.E. 33, desmantelándose igualmente todo el sector N. del muro U.E. 45 con la construcción de la U.E. 29 (Lám. VII). Pese a ello la cloaca se mantuvo en pleno funcionamiento actuando dicho muro como nuevo lateral oriental, colocándose las losas del lado O. de la cubierta apoyando sobre él (Fig. 3 B, Lám. V). Además el muro representado por la U.E. 29, que interceptaba la cloaca de forma perpendicular, presentaba una gran abertura para facilitar la evacuación del agua hacia el río.

Con los escasos elementos disponibles resulta imposible determinar la funcionalidad de la estructura que formaban las UU.EE. 29 y 33, cuya continuidad hacia el N. y O. era evidente. Las dos hiladas inferiores de ambos muros deben interpretarse como cimentaciones y el resto como alzados. La escasa superficie excavada al interior de estos muros correspondía a arenas geológicas (excepción hecha de algunas UU.EE. de época musulmana). Teniendo en cuenta el quiebro tan acusado que se origina en la topografía de la zona, que alcanza los 4 y $5 \mathrm{~m}$. podría apuntarse la posibilidad de que se tratara de un contrafuerte o estructura de contención del terreno.

El Corte 3 se ubicó en el sector centro sur del solar, sus dimensiones fueron de 5 x $4 \mathrm{~m}$. y fue el que más datos estratigráficos y estructuras aportó (Fig. 3). Se documentaron 27 unidades estratigráficas. Las unidades que más cantidad de material aportaron fueron las correspondientes a la fase tardorromana (UU.EE. 17, 18, $20 \mathrm{y}$ 22) con materiales cerámicos entre los que abundaban las africanas del tipo $\mathrm{C}$ (Hayes 50), A y D, así como TSH y TSG, estando igualmente representadas las africanas de cocina; pero sobre todo hay que destacar la gran cantidad de restos constructivos, en especial, los fragmentos de estuco con pintura mural monocroma (rojo, ocre, rosa, celeste, azulín), bícroma (blanco y rojo, ocre y rojo, rojo con bandas blancas) y policroma (verde, rojo y blanco; rojo, amarillo y blanco). Aparecieron también fragmentos de opus tessellatum y teselas de pasta vítrea, tégulas y ladrillos. Todos estos nive- 
les se han de considerar como de formación lenta, de derrumbe y abandono de las estructuras exhumadas, pertenecientes a un ambiente doméstico.

Mención especial merece la aparición en la U.E. 17 de abundantes fragmentos de una especie de tortas cóncavas de mineral fundido, cuya composición básica es plomo y cobre y sobre cuya problemática nos detendremos líneas abajo. El hallazgo de una pieza monetal correspondiente a un follis de Maximino Daza permitió fechar esta unidad a comienzos del s. IV d.C. La unidad situada inmediatamente debajo (U.E. 18), que correspondía a lentejón de cenizas de 2 a $5 \mathrm{~cm}$. de potencia, se dató a fines del s. III d.C. por la presencia de un antoniniano reducido sobre cospel de 20 $\mathrm{mm}$. del emperador Diocleciano acuñado en la $1^{\mathrm{a}}$ oficina de Alejandría.

En cuanto a estructuras, hay que anotar la aparición de una estructura muraria de sillares (opus quadratum) de arenisca miocena, que conservó tres hiladas desde su asiento, sobre las arcillas estériles (U.E. 25) sin zanja de cimentación. La disposición era isódoma y el estado de conservación pésimo, ya que sufrió el rebaje por su cara E. con el cimiento medianero (UU.EE. 3,4 y 5), encontrándose asimismo rota su continuación hacia el S. por la construcción de una noria de época musulmana (Lám. VIII).

Respecto del talud N. del tacón oriental existente en el solar hay que decir que los trabajos arqueológicos desarrollados se limitaron sólo a una limpieza superficial del perfil para reconocer las diferentes unidades estratigráficas, no habiendo sido posible una mayor documentación debido al peligro que suponía la presencia de unas viviendas de VIMCORSA que meses antes habían sufrido importantes desperfectos como consecuencia de una cimentación defectuosa.

En dicho talud N. se reconocieron como estructuras romanas las siguientes: la estructura $\mathrm{n}^{\circ} 1$ era una canalización de agua realizada con dos grandes imbrices opuestos, resultando una forma circular, con $27 \mathrm{~cm}$. de luz y $34 \mathrm{~cm}$. de anchura. Estaba excavada directamente sobre las arenas geológicas y se apreciaba perfectamente la fosa realizada para su construcción. Sobre ella se detectaron hasta cuatro estratos diferentes. Su cota era de 97.42 m.s.n.m. y su orientación N-S.

La que denominamos estructura $n^{\circ} 3$ consistía en un muro realizado con pequeñas piedras de arenisca y, sobre todo, con cantos rodados, con una anchura de $1 \mathrm{~m}$. y una altura de $2.30 \mathrm{~m}$. Su cota mínima era de $96.58 \mathrm{~m} . \mathrm{s} . n$.m. y la máxima de $98.88 \mathrm{~m} . \mathrm{s} . n . m$. Hacia la mitad de este muro se había colocado una gran losa de caliza micrítica (piedra de mina) en posición horizontal, seguramente para nivelación de los cantos rodados. La estructura $\mathrm{n}^{\circ} 5$ era semejante a la $\mathrm{n}^{\circ} 3$ siendo su anchura de $1.40 \mathrm{~m}$., la altura de $1.40 \mathrm{~m}$., mientras que la fosa excavada para su construcción tenía $1.74 \mathrm{~m}$. La cronología de estas estructuras no fue posible determinarla con la concreción que hubiésemos deseado pues el material cerámico recuperado de la limpieza superficial 
efectuada sólo sirvió para adscribir dichas estructuras a períodos históricos de forma muy general.

Fuera de contexto se descubrieron tres fragmentos que pertenecían a un mismo fuste de columna realizado en caliza marmórea de la sierra de Cabra, cuya altura total es de aproximadamente $1.5 \mathrm{~m}$. y un diámetro de unos $30-35 \mathrm{~cm}$. En la parte inferior se aprecia un ligero saliente o toro a modo de plinto y la mayor parte del fuste muestra una serie de rebajes que evidencian su amortización y posterior reutilización. Sin duda, lo más significativo es el resto epigráfico que conserva en el extremo superior, pues aunque está mutilado tanto hacia arriba como hacia la derecha, resulta de especial interés ${ }^{1}$.

Lo conservado se reduce a parte de una palabra con cuatro letras REST[ITUIT] o RES[TITUERUNT], cuyas características paleográficas nos remiten al s. III d.C., posterior a la época de los Severos (230-300), no llegando al s. IV d.C. En un primer momento, podríamos sospechar que nos encontramos ante un posible miliario, muchos de los cuales acaban en esa fórmula, pero si tenemos en cuenta que todos los miliarios hasta ahora conocidos en Córdoba son de caliza micrítica (ninguno de mármol de Cabra), unido al detalle del toro o plinto inferior de la pieza, hemos de concluir que estamos ante una columna reaprovechada como soporte de una inscripción. Con esa lectura que hemos propuesto inicialmente estaríamos ante una columna que formaría parte del edificio que se hubiese restituido o restaurado, pero al parecer esto no era lo habitual. También podría tratarse de una columna reaprovechada como pedestal de estatua, hecho frecuente durante los s. III-IV d.C. aunque en estos casos el último renglón de la fórmula epigráfica solía hacer mención del dedicante o algún detalle de la colocación, pago, etc.

Dado que existe la posibilidad de que la última letra pueda ser una $P$ la lectura podría restituirse de la siguiente forma RES P[UPLICA o RES P(UBLICA) CORDUBENSIS o CORDUBENSIUM]. Sabemos que Res publica era la forma habitual de autodenominarse los municipios y colonias a partir del s. II avanzado, y que la Colonia Patricia dejó de llamarse así hacia la $1^{a}$ mitad del s. III d.C. para volver a su viejo topónimo Corduba. Además, teniendo en cuenta que en estos momentos escaseaban las estatuas puestas a particulares o magistrados, no sería descabellado pensar que estemos ante un pedestal que sirvió de base a la estatua de un emperador. Por otro lado, teniendo en cuenta que la pieza fue reutilizada con posterioridad ignoramos si su ubicación originaria fue la zona del solar que se ha excavado, o si procede de cualquier otro punto de la ciudad.

\footnotetext{
${ }^{1}$ Nuestro agradecimiento al Prof. Armin U. Stylow, del Instituto Arqueológico Alemán, por sus apreciaciones en la interpretación del epígrafe.
} 


\subsection{C/ Poeta Ricardo Molina esquina Ronda de Isasa}

Las dos parcelas sobre las que se efectuó la intervención eran de morfología irregular en planta, con un suave desnivel entre los puntos extremos de su fachada a Ronda de Isasa, mientras que en sentido transversal presentaban un significativo salto topográfico que se materializaba tanto en la edificación existente en el interior de las parcelas (extremos occidental y oriental) como en su contorno medianero posterior en contacto con las fincas colindantes. Este desnivel queda evidenciado por las diferencias altimétricas existentes entre Ronda de Isasa, al S. con 96.5 m.s.n.m., y la Plaza de la Alhóndiga al N. con 101.8 m.s.n.m., así como por la presencia de la escalinata existente en la C/ Poeta Ricardo Molina. La diferencia entre ambas cotas alcanza los $5 \mathrm{~m}$.

Las parcelas afectadas tenían la siguiente superficie: la parcela $\mathrm{n}^{\circ} 3: 159.18 \mathrm{~m}^{2}$ y la $\mathrm{n}^{\circ}$ 4: $133.95 \mathrm{~m}^{2}$, con un total de $293.13 \mathrm{~m}^{2}$. Pero en función de lo estipulado por el Plan Especial del Río, y dada la longitud de la fachada afectada, la pérdida de superficie fue sustancial para dichas parcelas y, en consecuencia, para la excavación arqueológica. Se abrieron dos cortes localizados en los puntos extremos del solar, siendo la superficie total excavada de $53.5 \mathrm{~m}^{2}$. y las dimensiones de cada corte las siguientes: Corte $9.5 \times 5 \mathrm{~m}$. Corte $2: 3 \times 2 \mathrm{~m}$. Las referencias altimétricas de la excavación quedaron referidas a la cota actual del acerado $\mathrm{N}$. de Ronda de Isasa, justo enfrente de la C/ Poeta Ricardo Molina (96.32 m.s.n.m.).

Esta intervención apenas deparó resultados interesantes pues sólo una unidad estratigráfica, la U.E. 54, que representaba la primera fase de ocupación del lugar, correspondía a un estrato que pudo fijarse en torno a los siglos III-IV d.C., pues aunque contenía algunas cerámicas de época republicana como campanienses tipo $\mathrm{A}$ y $\mathrm{B}$, fragmentos de ánforas itálicas Dressel 1A, estaban asociadas a otros tipos más tardíos (sigillata africana tipo $\mathrm{C}$ ).

\section{La zona de la Ribera durante la época romana}

Los dos aspectos sobre los que vamos a centrar nuestra atención para conocer al papel desempeñado por este sector de la ciudad en la época romana giran en torno al urbanismo y la economía. Respecto del primero, hay que resaltar un dato significativo cual es la ausencia de estructuras anteriores al período augusteo. Las distintas excavaciones efectuadas no han puesto al descubierto ninguna estructura que cronológicamente pueda situarse en el s. II a.C. Sí se han recogido diversos materiales cerámicos encuadrables en el período republicano, tales como ánforas itálicas, campaniense A y B y cerámicas pintadas de tradición ibérica, pero como éstas aparecen asociadas a otras de cronología posterior (TSI, TSG y TSH), en ningún caso sirven para otorgar una datación, ni siquiera tardorrepublicana, a las estructuras con las que están 
relacionadas. También se hallaron, fuera de su contexto originario, varios fragmentos de cerámicas hechas a mano, en concreto en el Corte 1 del solar de C/ Caño Quebrado y en los Cortes 1 y 2 de Ronda de Isasa, 4, correspondientes todos a bordes de cazuelas de carena alta y de superficies bruñidas, cuya tipología es bien conocida, debiendo fecharse en un momento avanzado del Bronce Final, hacia el s. IX a.C.

La presencia de este material arqueológico anterior a la época de Augusto en la zona que nos ocupa puede deberse a diversos factores, incluso podría obedecer a la existencia de un hábitat puntual y disperso junto al río pero, en ningún momento, es razón suficiente para pensar en una ocupación in extenso, de modo que puede afirmarse que la Córdoba fundacional y republicana no llegó hasta el río como creían algunos autores. Esta teoría ya había sido expuesta anteriormente (SANTOS, 1955: 199-200; VENTURA et alii, 1996: 89-90) y se confirma ahora con los datos obtenidos en las diferentes excavaciones de La Ribera. Sería inmediatamente después de la batalla de Munda cuando la ciudad comienza a reconstruirse al hilo de toda una serie de transformaciones que permiten hablar de una Córdoba renovada (VENTURA, 1996: 140-142). Corduba alcanza el rango de colonia civium romanorum y recibe un nombre prestigioso Colonia Patricia (SYTLOW, 1990: 263 y 1996: 79-80; KNAPP, 1983: 29; RODRIGUEZ NEILA, 1988: 214 y 2959) que aparece, por primera vez, en una serie monetal acuñada por la propia ciudad (CHAVES, 1977: 102). Además, la ciudad, que anteriormente había sido caput provinciae, como relata el Bellum Hispaniense, continua manteniendo un papel importantísimo al ser capital de la provincia Hispania Ulterior Baetica, así como del conventus cordubensis. La vetusta Corduba republicana de piedra caliza se transforma y convierte en la Colonia Patricia marmórea. Por otro lado, la filiación augustea del proyecto supone un proceso de cambio de apariencia que se concentra bajo los principados de Augusto y Claudio como lo denuncian los tipos arquitectónicos y los paradigmas escultóricos utilizados (LEÓN, 1996: 22).

El hecho crucial que explicaría de manera satisfactoria la ampliación de la vieja Corduba hasta el río sería el notable crecimiento de población como consecuencia directa de la deductio de veteranos de las Guerras Civiles y Cántabras para fomentar la explotación agraria del territorio (VENTURA, 1996: 142), hipótesis basada en los motivos legionarios que vemos en el reverso de las monedas de Colonia Patricia. De las $42 \mathrm{Ha}$. iniciales se pasó a las $78 \mathrm{Ha}$. que llegó a tener la nueva urbe.

\subsection{La trama viaria de la zona}

En esas 36 nuevas hectáreas, que supuso la ampliación de la ciudad, se trazó, ex novo, una amplia red de calles perpendiculares entre sí, con sus correspondientes cloacas, delimitando manzanas o insulae (VENTURA, 1996: 142), constituyendo la 
innovación más llamativa la solución dada al problema representado por la anexión de la parte baja, que consistió en aplicar la fórmula de la organización del espacio en terrazas (LEÓN 1996: 23). Los cardines que en la parte alta de la ciudad tenían una orientación N-S., paralela a las murallas, adoptan ahora un trazado NO-SE. Testimonios de esa ampliación serían los cardines documentados en los solares de la C/ Caño Quebrado, 3 (Fig. 2A) y en Ronda de Isasa, 4 (Fig. 2B) y, probablemente también, el descubierto en el sector SE. del recinto amurallado, en concreto en el solar de la $\mathrm{C}$ / Amparo $\mathrm{n}^{\circ} 5$ y 7 recayente a Ronda de Isasa, con motivo la excavación dirigida por Dñ $\tilde{n}^{\mathrm{a}}$ Laura Aparicio, así como el que vio Félix Hernández bajo la Mezquita, actualmente en estudio por D. Pedro Marfil.

Ignoramos si el kardo de Ronda de Isasa, 4 disponía de una o dos cloacas. Es posible que sólo existiera una, que no necesariamente debía discurrir por el eje de la calle, pues estos sistemas de drenaje van adaptándose a la topografía natural del terreno. Pero también podría tener una bajo cada acera como ya se ha documentado en algunos ejes viarios, en concreto bajo el kardo maximus (VENTURA et alii, 1996: 106-107). La cloaca detectada por nosotros sería la más oriental, mientras que la otra estaría en el extremo opuesto, que no pudimos investigar. En consecuencia, la cronología augustea que presuponemos a estas unidades vendría determinada, de forma indirecta (no hallamos material arqueológico que permitiera su datación) por hallarnos en la zona que fue objeto de una urbanización realizada ex profeso durante el mandato de Augusto y por la datación posterior de las UU.EE. 29 y 33.

No es mucho lo que podemos decir de estas calles pues ni la excavación del solar de C/ Caño Quebrado, 3 ni el de Ronda de Isasa, 4 permitieron documentar por completo ambos ejes viarios, ignorándose la anchura de cada uno (en el mapa de la Fig. 1 hemos señalado el eje de las dos cloacas, correspondiendo la de C/ Caño Quebrado, 3 a la letra A y la B a Ronda de Isasa, 4). El pavimento estaba formado por grandes losas de un conglomerado tipo pudinga idéntico al que presentan otras calles de la ciudad. Como sabemos, éste fue el material empleado en la pavimentación de las calles con motivo de la amplia reforma efectuada en época de Augusto y cuyas canteras se encuentran a escasa distancia de la ciudad. En C/ Caño Quebrado, 3 sólo aparecieron varias losas in situ, mientras que en Ronda de Isasa, 4, había algunas de éstas losas pero en posición secundaria. Bajo los pavimentos estaban las correspondientes cloacas, de grandes proporciones, construidas con losas de arenisca (calcarenita) empleadas tanto en la base, las paredes y cubierta. En el primer caso, la caja de la cloaca era ligeramente rectangular (más alta que ancha) y su cubierta adintelada (Fig. 3A), mientras que en el segundo la cubierta que debía resolverse inicialmente a dos aguas, sufrió una ligera remodelación varios siglos después aunque mantuvo parte de esa cubierta (Fig. 3B). En ambos casos, las zanjas están abiertas directamente sobre el terreno estéril correspondiente a arenas 
cuaternarias del río. Ambos tipos de cloacas encajan perfectamente en la tipología establecida para la red de saneamiento de la ciudad en época augustea (VENTURA, 1996: 126, Fig. 127 B y C).

Desde luego, los datos que más interesan son la ubicación exacta de estas dos calles y su orientación, de tal modo que puede recomponerse con evidencias arqueológicas firmes el entramado urbano de este sector, al menos para los cardines, teniendo en cuenta que el proyecto de ampliación de la ciudad se adaptó a un plan ortogonal. Para esta zona se ha propuesto que las insulae podrían tener unas dimensiones de 35x70 m., es decir, 2 actus (VENTURA, 1996: 142), cifra que se aproxima a la distancia existente entre los cardines de C/ Caño Quebrado, 3 y Ronda de Isasa, 4 (entre cloaca y cloaca hay unos $50 \mathrm{~m}$.), con una clara orientación NO-SE., casi perpendicular al muro defensivo meridional (Figs. 1 y 2). Teniendo en cuenta esta distancia fija entre cardines deberíamos haber detectado los tramos finales de al menos otras dos vías, una en Ronda de Isasa, 4 y otra en C/ Poeta Ricardo Molina, pero la erosión histórica lo ha impedido.

\subsection{El tramo E. de la muralla defensiva meridional}

Por lo que se refiere al muro defensivo meridional hemos de recordar que constituye el lienzo más escurridizo. Sobre su trazado existe una gran polémica (LÓPEZ, 1981: 74; IBAÑEZ, 1983: 297-299; SYTLOW, 1990: 265-267; KNNAP, 1983: 53; VENTURA et alii, 1996: 91-93), no resuelta aún de forma satisfactoria ante la ausencia de restos arqueológicos contundentes. Puede afirmarse que existieron dos lienzos de murallas que protegieron la ciudad por el S. El primero dataría del período republicano y sobre su trazado concreto no existen evidencias palpables que permitan ubicarlo con precisión, aunque se intuye su localización aproximada. Debía discurrir justo por el reborde elevado de la terraza del Guadalquivir, entre los solares documentados con/sin restos republicanos (VENTURA et alii, 1996: 90), habiéndose apuntado la posibilidad de que un potente muro localizado en la $\mathrm{C} / \mathrm{Ambrosio}$ de Morales, 17-19 con trazado NE-SO. y adosado al lienzo de la muralla E. de la ciudad, justo en el punto en que ésta sufre una inflexión en su traza (MARCOS-VICENTCOSTA, 1977: 224-225), correspondiese al muro S. republicano.

Estos datos podrían completarse con las noticias transmitidas por algunos cronistas árabes para quienes la Medina estaba dividida en dos zonas. Basándose en la cita de Aben al-Jatib según la cual la Medina propiamente dicha o alcazaba había que contarla por dos, una que abarcaba la mezquita mayor y sus alrededores y otra la situada dentro del antiguo recinto, cada una de las cuales poseía su propio jefe y puestos de vigilancia, R. Castejón dice que la Medina estaba separada en dos sectores 
diferentes por un muro, identificando el recinto amurallado superior o septentrional con la primitiva urbs quadrata republicana (CASTEJÓN, 1964: 374). En consecuencia, ese muro divisorio podría corresponder a la muralla meridional de la ciudad republicana, muro que se mantendría en pie al ampliarse la ciudad hasta el río, donde se levantó otra nueva muralla para cercarla por ese sector.

Sobre el trazado de esa nueva muralla meridional también existe gran polémica, quedando ésta sin plasmar en algunos de los planos de la ciudad que reproducen el perímetro amurallado (STYLOW, 1990: 264; MARCOS-VICENT, 1985: Fig. 1). Hoy día el tramo occidental, es decir, el que va desde la Puerta del Puente hasta el punto donde éste conectaría con el lienzo O., se conoce algo mejor que el opuesto, o sea, el que va desde dicha puerta hasta la Cruz del Rastro. Veámos los datos de que disponemos en ambos casos.

Respecto del primer tramo se conocen algunos restos que han sido identificados como pertenecientes a las murallas romana y musulmana. Su detección tuvo lugar con motivo de las tareas de restauración del Alcázar de los Reyes Cristianos, en cuyo Patio de Mujeres, se encontraban sendos muros de sillería contiguos interpretados como pertenecientes a la cerca romana el situado al $\mathrm{N}$. y a la muralla de la madina árabe el meridional. Se ha restituido todo el ángulo SO. de la cerca, desde su conexión con el lienzo O., donde termina el muro $S$. de las albercas ubicadas en la zona de los jardines altos del Alcázar, hasta la Puerta del Puente pasando por la fachada meridional del Seminario de San Pelagio (MONTEJO-GARRIGUET, 1994: 243276). Pero no creemos que todo el trazado del lienzo meridional completo fuese recto, pues si esa línea la prolongáramos hacia el E., hasta la C/ San Fernando, pasaría justo por medio de los solares de la C/ Caño Quebrado, 3 y Ronda de Isasa, 4, en los que no se exhumó ninguna estructura defensiva, por lo que en principio cabrían dos posibilidades, la primera que la muralla discurriese al N. y, la segunda, que se encuentre al S. Si tenemos en cuenta la presencia de los cardines, que se prolongan hacia el S. llegando hasta la misma línea actual de fachada, hecho que pudo verse en los trabajos de seguimiento en el solar de la C/ Caño Quebrado, 3 y que otros muros romanos continúan, igualmente, en la misma dirección (lo mismo ocurre con las estructuras musulmanas), podemos deducir que el espacio excavado se hallaba intramuros, de modo que la muralla debe ubicarse, probablemente, en la misma línea de fachada de Ronda de Isasa (como hemos reflejado en el plano de la Fig. 1 mediante un trazo grueso), aunque podría estar incluso bajo la actual carretera. De lo contrario, o sea, en el caso de que la muralla estuviese al N., no tendrían sentido unas calles pavimentadas fuera del recinto amurallado, ni la situación fuera de él de unas edificaciones (tanto romanas como musulmanas) que sufrirían inevitablemente las consecuencias de las continúas y devastadoras crecidas del río. 
Aunque en estos dos solares no se pudo excavar en la zona más próxima a la actual fachada a la avenida de Ronda de Isasa, en el solar sito en la C/ Amparo $\mathrm{n}^{\circ} 5 \mathrm{y}$ 7 , sí fue posible, y en dicha zona apareció el único resto que podría estar en relación con la muralla meridional. Se trata de un muro de unos $7 \mathrm{~m}$. de longitud y $2.50 \mathrm{~m}$. de anchura, separado unos 4-5 m. de la línea de fachada a la citada avenida, que fue interpretado como perteneciente a la muralla meridional de la ciudad por la directora de la excavación. En nuestra opinión, dicho muro no parece tener la entidad que presenta la muralla en otros sectores, pudiendo tratarse, más bien, del muro de contención del agger, que suele separarse de la muralla propiamente dicha unos $6 \mathrm{~m}$.

Según parece aún existían restos de murallas en ese tramo en siglo pasado, pues al referirse Ramírez de Arellano al murallón de la Ribera expone: "Por los trozos de muralla, unos caidos y otros en pie, que se encuentran desde la Cruz del Rastro al Puente, y muchos que se han desbaratado en las obras de la nueva, se vé aunque de diversas construcciones, que desde tiempo inmemorial, aun antes tal vez de los romanos, estaba Córdoba defendida de las aguas del Guadalquivir con un murallón, que á la vez serviria para su defensa" (RAMIREZ, 1995: 299). Por otro lado, con anterioridad, en el s. XVI, cuando se inició el proceso de configuración de la Ribera como un paseo en tramos sucesivos, se llevaron a cabo diversas obras, como las ejecutadas en 1553 para hacer un paseo y andén desde el Rastro, al final de la calle de la Feria hasta la Puerta del Puente, que al parecer se hicieron sobre restos de la antigua muralla, según consta en el acta capitular de ese año (PUCHOL, 1992: 148). Algunas fotografías antiguas también parecen mostrar restos de potentes construcciones en esta zona. De entre ellas destacamos una retrospectiva de la Ribera, realizada por Basilio Alcañiz hacia 1890, conservada en el Archivo Municipal de Córdoba, en la que se aprecian restos de gruesos muros de sillería, junto a la misma orilla, que pudieran haber formado parte de las defensas de la ciudad (Lám. IX).

\subsection{Evidencias de una instalación oleícola}

Toda una serie de restos hallados en los cuatro cortes abiertos en el solar de la C/ Caño Quebrado, 3 nos llevan a plantear la posibilidad de que allí se hubiese ubicado algún tipo de instalación industrial relacionada con la elaboración, almacenaje y transporte de aceite. En primer lugar, las propias ánforas Dressel 20-23 cuya relación directa con el transporte del aceite bético está suficientemente probado. De los diversos tipos de ánforas usados para tal fin, sobresale la llamada "ánfora globular hispánica", correspondiente al tipo Dressel 20, que se caracteriza por su cuerpo globular, un peso en vacío de unos 30 kilos y una capacidad de 70 kilos de aceite; suelen presentar unas marcas impresas en las asas y unos letreros pintados con tinta negra 
(tituli picti) que indicaban la tara del ánfora, el peso del contenido neto, el nombre del comerciante o transportista y una especie de control fiscal entre cuyos datos figura la fecha de expedición del recipiente (CHIC, 1988; RODRIGUEZ ALMEIDA, 1989; PONSICH, 1984). Habría que señalar también la presencia de las tapaderas halladas en la excavación, tapaderas que se empleaban para este tipo concreto de ánforas olearias (Lám. IV). Se caracterizan por tener una forma circular, con un diámetro de $7-8 \mathrm{~cm}$. con un resalte o pico cóncavo en el punto central de la parte superior o anverso, mientras que en el reverso se origina una ligera convexidad (RODRIGUEZ ALMEIDA, 1980: 171, Fig. 70).

Tanto las ánforas como las tapaderas podrían hacernos pensar que estamos ante una figlina, pero no detectamos ningún indicio al respecto (instrumentos de alfar, fallos de cocción, etc.). Las fábricas de ánforas Dressel 20 se suceden en el Guadalquivir a lo largo de un recorrido de $160 \mathrm{~km}$. con una intensidad progresiva desde abajo hasta arriba, coincidente con la navegabilidad del río y con una regularidad que demuestra el aumento de la densidad de producción del aceite, a medida que se remonta el río en dirección a Corduba (PONSICH, 1980: 47-56). En cualquier caso, resulta llamativa la inexistencia de figlinae tanto en las cercanías de Corduba (la fábrica de ánforas más septentrional se localiza en el Cortijo de la Reina) como aguas arriba. Se piensa que en estas zonas el transporte del aceite se haría preferentemente en odres de pellejo, más apropiado para su traslado con carros y a lomos de animales hasta el puerto más cercano donde el río fuese navegable. El aceite se trasvasaría allí de los odres a las ánforas embarcándose vía fluvial (PONSICH, 1987: 12-13). Sabemos, gracias a los tituli picti, que Corduba fue un importante distrito fiscal o centro del control del aceite bético, pero pese a ello apenas tenemos noticias sobre la producción de aceite en la propia capital o sus alrededores, aunque podemos mencionar sendos relieves, conservados en el Museo Arqueológico de Córdoba, en los que aparecen diversas escenas relacionadas con la recogida de la aceituna. Esta situación puede obedecer a la especial ubicación de las almazaras emplazadas, seguramente, fuera de la población. Tan sólo sabemos que en la villa situada en el complejo arqueológico de Cercadilla pudieron existir varias prensas de aceite, de las que tan sólo se ha conservado la cimentación de losas de pudinga, dispuestas en una gran plataforma trapezoidal, habiéndose detectado también el posible prelum usado como contrapeso (MORENO, 1997: 53-54, Fig. 18). La existencia de fábricas de aceite está, en cualquier caso, comprobada aguas arriba de Córdoba hasta la zona de Castulo como demuestra la epigrafía (BLANCO, 1962) y también en otros lugares de la provincia cordobesa, caso de las serranías Subbéticas a juzgar por los numerosos testimonios arqueológicos hallados: pies de prensa, soportes de arbores, contrapesos, etc. (CARRILLO, 1995). 
En consecuencia, tanto las ánforas como las tapaderas podrían estar en relación con la zona de almacenaje (cella olearia), o más bien, con el transporte directo del aceite hacia sus lugares de destino, pues no parece que en las grandes ciudades, como se ha comprobado en Volubilis y zona del N. de Siria, las cantidades de aceite obtenidas fuesen lo suficientemente importantes como para exigir la construcción de almacenes, procediéndose al envase directo del producto para su rápida comercialización (BRUN, 1986: 135-136).

Otros hallazgos que proporcionó la excavación fueron los siguientes. Dos fragmentos de fustes de mármol encontrados en el Corte 2 (U.E. 9) que podrían estar de alguna manera relacionados con la sala de prensado o torcularium. Ambos corresponden a fustes diferentes y fueron reaprovechados, presentando ambos sus extremos planos. Uno de ellos presentaba una mortaja, en un extremo, en forma de cola de milano, que recuerda las existentes en los contrapesos empleados en prensas de aceite, sobre todo, en prensas de cabrestante o de torno. Para algunos autores, en estas mortajas irían colocadas unas piezas de madera lo suficientemente largas para soportar otra pieza también de madera, en la que iría introducida la parte final del tornillo de la prensa, sin alcanzar la superficie de la piedra, de ahí que algunos contrapesos no presenten el típico orificio central (DRACHMANN, 1932: 97, Fig. 32). El otro fuste no tiene ningún tipo de mortaja ni orificio pero en el N. de Africa, concretamente en Volubilis, existe un tipo de molinos de aceite llamados "à galerie-gouttière" con un pivote central, que recuerda un tambor de columna sin rebaje de ningún tipo (ETIENNE, 1960: 83).

Por otro lado, el opus signinum sabemos que se empleó como pavimento y revestimiento impermeabilizante en obras hidráulicas ya contuviesen éstas agua, aceite, vino, etc. En ocasiones llegó a constituir el propio pie de prensa, sin canal, pero la inclinación que ofrece el suelo hallado en el Corte 2, que pese a lo escaso conservado es bastante acusada, bien podría indicarnos que se trata del suelo de un tabulatum, es decir, una dependencia en la que la aceituna se almacenaba durante un tiempo para mejorar su rendimiento. Esta dependencia estaba dotada, según los agrónomos latinos, de un entarimado de madera dispuesto sobre pilares y con el suelo inclinado para eliminar la amurca, o sea, el alpechín que nunca debía mezclarse con el aceite.

Otro de los testimonios, hallados durante el seguimiento, que apunta a una instalación oleícola, es un gran cubo de plomo, en cuyo interior, por cierto, había fragmentos de un ánfora olearia. Sabemos, por los agrónomos latinos, que una vez prensada la aceituna, el líquido debía ser conducido a una serie de depósitos para ser decantado, teniendo especial cuidado en no mezclar el aceite del primer prensado, el de mejor calidad, con los de prensados sucesivos; a continuación el aceite era trasvasado de unos recipientes a otros para purificarlo hasta almacenarlo en grandes dolia (CARRILLO, 
1995: 67). A este respecto Columela (De re rustica, XII, 52, 10) dice que el primer aceite debía caer en cubas redondas de plomo que eran preferibles a las cuadradas.

Para establecer la cronología de esta fábrica poseemos una fecha post quem que viene marcada por el hallazgo, entre los cantos rodados de la U.E. 16, que corresponde a la cimentación del pavimento de opus signinum, de un pequeño fragmento amorfo de cerámica de engobe rojo pompeyano y otro de TSG decorada. En la U.E. 20 que cubría el suelo de mortero se recogió cerámica común y algún fragmento de TSH. Por lo tanto, la construcción del pavimento podría fijarse en el s. I d.C. habiendo estado en funcionamiento durante esa centuria y la siguiente, al menos. Respecto de las ánforas Dressel 20 apenas podemos decir nada ante la falta, en la mayoría de los casos, de la parte superior, de manera que no poseemos los elementos clave para fecharlas con exactitud, caso del tipo de borde o las marcas que aparecen en las asas. Estas ánforas se fabricaron desde época de Augusto hasta el s. III d.C., fecha en que son sustituidas por el tipo conocido como Dressel 23, coincidiendo con el fin del Testaccio (REMESAL, 1984: 129 y 1989). Son de menor volumen y su perfil es más oval que globular, asemejándose más bien a grandes cántaros y presentando además ciertas variaciones en la forma del labio (RODRIGUEZ ALMEIDA, 1980: 155, Fig. 63). En la excavación las ánforas aparecen, junto con las correspondientes tapaderas, desde los primeros momentos de ocupación del solar, en contextos de mediados del s. I d.C.; en las UU.EE. 27 y 28 del Corte 3 situadas bajo el pavimento de la calle, aparecen asociadas a TSI y TSG, paredes finas, barniz rojo julio-claudio, y a otros materiales más antiguos (pintadas de tradición ibérica, ánforas itálicas, barniz negro); en el Corte 4 las vemos en el primer nivel de ocupación (U.E. 14) junto con cerámicas de paredes finas, lucernas, TSI, TSG y marmorata, así como otros materiales cerámicos más antiguos. Pero también aparecen en niveles superiores del s. II d.C., junto con TSH y africanas de cocina, indicando posiblemente la perduración de estas instalaciones aceiteras, incluso durante el s. III d.C. por la presencia de algún borde del tipo Dressel 23.

En el solar de Ronda de Isasa, 4 se hallaron igualmente algunos fragmentos de ánforas Dressel 20 y sus correspondientes tapaderas, que en algunos casos se emplearon reaprovechados como cuñas en la construcción de diversas estructuras tardorromanas y musulmanas. Aparecieron en la U.E. 49 perteneciente al sedimento de colmatación de la cloaca U.E. 50 del Corte 1, en la U.E. 17 del Corte 3 datada a fines del s. III d.C., etc.

\subsection{Actividades metalúrgicas}

Que la minería fue una de las riquezas hispanas más exaltadas por los autores antiguos es de sobra conocido, y que dicho sector económico tuvo un papel destaca- 
do la Bética, cuya capital debió en parte su prosperidad a la densidad minera de Sierra Morena. Pese a ello el conocimiento que hoy tenemos sobre la realidad de la minería antigua en el N. de la provincia de Córdoba deja mucho que desear, si bien, contamos con algunos trabajos que resultan de consulta obligada para conocer en toda su extensión la problemática minera de dicha zona (DOMERGUE, 1987 y 1989; MÁRQUEZ, 1983 y 1984; BLÁZQUEZ, 1982-1983; VAQUERIZO, et alii, 1994; RODRÍGUEZ NEILA, 1988). Sin duda, de los variados recursos mineros existentes sobresalían el cobre y el plomo argentífero que eran tratados bien in situ, para ser transformado en lingotes en las cercanas fundiciones, o despachado en bruto con otro destino, siendo la vía natural de salida el camino que seguía el curso del río Guadiato, por donde en época imperial se trazó la vía que unía Corduba con Emerita (RODRÍGUEZ NEILA, 1988: 387; MELCHOR, 1993: 64-69; CORZO-TOSCANO, 1992: 182-185). Debieron utilizarse igualmente otras vías secundarias como el llamado "Camino del Pretorio", considerado como un camino minero propiamente dicho y cuya razón de ser estaría en relación con la explotación de las minas cercanas a Córdoba y de las existentes en la margen derecha del río Guadiato (MELCHOR, 1993: 76-77), aunque a través de él se daría salida a otros productos como el cinabrio y el mercurio de la región de Almadén (VENTURA, 1993). En la capital los productos serían cargados en barcos que descenderían por el Guadalquivir hasta Gades desde donde se expedirían hacia Roma (DOMERGUE, 1972: 614). Pero esa fase de fundición se ha constatado igualmente en zonas alejadas de los propios filones, en concreto, junto al Guadalquivir en Posadas, a poca distancia del cauce fluvial (DOMERGUE, 1972: 616), lo que también se ha documentado en el solar excavado en Ronda de Isasa, 4 como a continuación detallamos.

La aportación que presentamos en este articulo sobre metalurgia responde a los datos ofrecidos por el Corte 3 de la excavación efectuada en Ronda de Isasa, 4. Más concretamente nos referimos a la U.E. 17, correspondiente a un nivel de arcillas pardorrojizas, de unos $60 \mathrm{~cm}$. de potencia media, que contenía abundantes restos constructivos como tégulas, laterculi, ímbrices, fragmentos de opus tessellatum y teselas de pasta vítrea, así como abundantes restos de pintura parietal (monocroma o bícroma, motivos de bandas rojas sobre fondo ocre o blancas sobre fondo rojo, fondos monocromos rojos). La cronología de este episodio estratigráfico hay que centrarla en el paso del siglo III d.C. al s. IV d. C., ya que, a pesar de la presencia de materiales cerámicas antiguos (como cerámicas pintadas de tradición ibérica, fragmentos amorfos de TSH, campaniense B y ánforas itálicas Dressel 1A, los materiales cerámicos más modernos así lo indican: producciones africanas, tipos $\mathrm{C}$ (Hayes 50) y $\mathrm{D}$, junto a un follis reducido de bronce sobre cospel de $20 \mathrm{~mm}$. de Maximino Daza, fechado en el 313-314 d. C. de la ceca de Constantinopla. 
Lo más destacable dentro de este nivel fue la aparición de grandes cantidades de metal con una forma predeterminada: se trata de múltiples fragmentos metálicos de forma circular y cóncava, con un espesor que oscila entre los 27 y $15 \mathrm{~mm}$., aunque no se encontró ninguno completo. El diámetro máximo en uno de ellos es de unos 270 $\mathrm{mm}$. La alta densidad de estas tortas nos hizo pensar, desde un primer momento, en la existencia de metales pesados hipótesis que se vio confirmada por los posteriores análisis realizados en una muestra. La analítica realizada ${ }^{2}$ se efectuó con la técnica EDAX, usando un microscopio electrónico de barrido, y técnica de difracción de Rayos X. El resultado en porcentajes de elementos reconocidos fue el siguiente: Plomo $(\mathrm{Pb}) 38.2 \%$ Oxígeno (0) $27.6 \%$, Cobre $(\mathrm{Cu}) 13.2 \%$, Calcio (Ca) $12.6 \%$, Carbono (C) $4.0 \%$, Silicio (Sî) $3.2 \%$, Aluminio (Al) $0.7 \%$, Hierro (Fe) $0.5 \%$. De él se desprende como primera conclusión que el beneficio metálico preferente fue el plomo. La presencia de un alto porcentaje de oxigeno debe estar en íntima relación con la necesaria atmósfera oxidante que se requiere en cualquier proceso de fundición metálica. La presencia de un $13 \%$ de cobre responde a la existencia de un pequeño núcleo de $3 \mathrm{~mm}$. de espesor que debe interpretarse como circunstancial y que, sin duda, altera la relación porcentual de elementos reconocidos.

Las tortas metálicas presentaban una superficie oxidada con pátina blanquecina, aspecto que responde, según el resultado de la analítica realizada, a la detección de óxidos y carbonatos de plomo y cobre (cerusita y malaquita, ésta última con su característico color verde). No han aparecido restos de azufre, descartándose la existencia de sulfuros o sulfatos, tanto de residuos del metal una vez fundido, como de restos de la mena. Por otro lado, la aparición de silicio, aluminio, hierro y calcio puede deberse a los componentes químicos que caracterizaban el sedimento pardorrojizo que envolvía los restos de las tortas metálicas.

Las muestras que aparecieron en este corte representan uno de los muchos indicios y elementos que caracterizaron la explotación de los recursos mineros de la Baetica, durante el periodo romano. Para saber exactamente a que fase del proceso metalúrgico corresponden los restos documentados en Ronda de Isasa, 4 tendremos que acudir a las fuentes clásicas y a las evidencias arqueológicas que hasta el presente poseemos, centrándonos básicamente en los diferentes procesos de tratamiento del metal. Sabemos que la actividad metalúrgica en sí se compone de diferentes pasos, que apenas han variado desde la prehistoria hasta la actualidad (BATERMAN, 1978).

\footnotetext{
${ }^{2}$ Los análisis se efectuaron sobre una muestra de estas tortas metálicas por el Dr. Vidal Barrón de la Escuela Técnica Superior de Ingenieros Agrónomos de la Universidad de Córdoba. Desde aquí agradecemos todas las facilidades ofrecidas por dicho investigador, ya que parte del presente trabajo no podría haberse realizado sin su ayuda desinteresada.
} 
De todos ellos (trituración, molturación, escorificación y fundición) el que más nos interesa es el de la fundición.

Este proceso consiste en la fusión de la mena de forma directa, o previamente escorificada, de la que se obtiene el metal. Esta fase consiste en la introducción de la mena en el interior de la cámara del horno alternando bloques de mineral con fragmentos de carbón, material vegetal y fundentes. Las características de estos últimos dependen del tipo de mena del que se desea obtener. De este modo si se trata de galena ( $\mathrm{PbS}$ ) los más apropiados son el carbono, cobre, oxido de hierro o calcio, ya que la reducción de posibles silicatos de plomo a plomo puro es más rápida y se produce a temperaturas más bajas. El óxido de plomo es reducido por el carbono, los silicatos asociados a la galena se descomponen con el óxido ferroso quedando en libertad el óxido de plomo, que a su vez es reducido por el carbono a plomo puro.

Las escasas evidencias arqueológicas referentes a hornos romanos de fundición metalúrgica que existen se refieren a cuatro casos, todos ellos con la característica común de encontrarse situados en las proximidades de las propias minas. Se trata de los tres hornos aparecidos en Mestanzas (Ciudad Real); las tres zonas de fundición en el área de las minas del Centenillo, en Baños de la Encina (Jaén): Coto Fortuna con tres grandes fundiciones de galena argentífera, la Fabriquilla con una fundición y el Cerro del Plomo; el horno de Los Gavilanes (Mazarrón, Murcia), fechable en los siglos IV-III a. C., de explotación púnica, insertado en el complejo minero de Carthago Nova; y por último el excavado en Las Herrerías (Mazarrón, Murcia), de época republicana.

Los datos aportados para los hornos de Jaén (BLÁZQUEZ, 1978: 40, 88-89) no concretan aspectos tales como el uso, tipología, destino, y partes del mismo, aunque poseen una adscripción cronológica de los siglos II a. C. al II d. C. El caso de los tres hornos de Ciudad Real (MÁRQUEZ, 1983) podemos considerarlos como un caso excepcional, ya que se encontraron cargados de mineral y combustible sin fundir. Los hornos se encontraban excavados en la roca, una pizarra arcillosa, poseían unos $4 \mathrm{~m}$. de diámetros por $2 \mathrm{~m}$. de altura. El mineral era plomo argentífero, alternando éste con lechos de leña y fundente. Uno de estos hornos se vació conteniendo 14.000 $\mathrm{kg}$. de galena argentífera. En su eje aparecía una chimenea vertical de $25 \mathrm{~cm}$. de diámetro, hecha de arcilla. La forma de la cámara era de cúpula, cuyo interior se encontraba revestido de arcilla y en la base, excavado en la propia roca se encontraba una cazoleta o crisol para recoger el metal. Por encima del crisol aparecía el conducto de tiro, a modo de trinchera, de $30 \mathrm{~cm}$. de diámetro decreciente con la distancia. Como fundentes se usaron la caliza y el óxido de hierro.

Para el caso del horno de Los Gavilanes de Mazarrón (RAMALLO et alii, 1994: 87) son interesantes los datos aportados durante la excavación, ya que se documentó 
la planta, de forma circular, y excavado en la roca al igual que los de Ciudad Real. Junto al mismo aparecieron dos cubetas de decantación realizadas con material refractario situadas en forma escalonada. Este horno se dedicó al beneficio de la plata contenida en la galena de la zona. Otro ejemplo de horno de fundición aparece en la misma zona minera en Las Herrerías (Mazarrón), excavado en las margas de base pero en este caso fechado en los siglos II y I a. C. (RAMALLO, et alii, 1994: $112 \mathrm{ss).}$ En estrecha relación con el horno aparecieron tres cubetas escalonadas usadas para el proceso final de refinado. En la segunda apareció un hueco en su borde superior a modo de compuerta con la tercera pileta. Los restos de escorias aparecidos inducen a pensar igualmente en el beneficio de la plata desde galenas argentíferas.

Como hemos visto un elemento indispensable es la oxigenación del horno, bien buscando una orientación favorable al viento, bien por la aplicación artificial, a través de fuelle, toberas de aire o zanjas de aireación. La fundición de la ganga va a parar al crisol o piletas en las que sobreemana la escoria del plomo, quedando este último en la parte inferior del mismo. Estos procesos de reducciones hacen de la escoria una masa homogénea y flotante fácilmente separable del plomo puro.

El plomo obtenido, separado ya de la escoria, queda en otra pileta, junto al horno, sacando el metal con un cazo, para verterlo en lingoteras. Es normal la concreción de parte del metal a estos cazos, que se separaban cada cierto período de tiempo a golpes de martillo. Los restos aparecidos en la U.E. 17 deben corresponder a las rebabas o concreciones que quedaban en estos cazos. La aparición únicamente de fragmentos y nunca una torta completa, así como las características propias del metal: plomo y oxígeno puros, apuntan a un proceso de limpieza periódica de estos cazos a golpe de martillo. El hecho de la presencia de pepitas de cobre puede interpretarse como adherencias en las paredes del cazo, suponiendo una utilización previa de éste en la obtención de lingotes de cobre. No ha lugar a interpretar estos fragmentos metálicos como parte de lingotes propiamente dichos destinados a su comercialización pues la tipología de lingotes de plomo es bien conocida (DOMERGUE, 1956; VENY, 19691970; VENY-CERDÁ, 1972).

Respecto de la procedencia del mineral es casi seguro que debe tratarse de un yacimiento filoniano de relleno de fractura, próximo al contacto igneo-sedimentario de óxidos polimetálicos (que en profundidad deben ser sulfuros polimetálicos) muy abundantes en las mineralizaciones de Belmez-Cerro Muriano (concretamente podría ser del Paredón, de las Berrazas, de Mirabuenos-La Campana o de Cerro Muriano, lugares todos ellos asociados al mencionado eje magmático de Belmez-Cerro Muriano) ${ }^{3}$.

\footnotetext{
${ }^{3}$ Información que agradecemos a D. Antonio Daza Sánchez, Profesor Titular de Prospección e Investigación Minera en la Escuela Universitaria de Ingeniería Técnica de Minas de Belmez.
} 
Las evidencias arqueológicas encontradas en el Corte 3 de Ronda de Isasa, 4, apuntan a la existencia en este punto concreto de la ciudad, junto al río, de hornos de fundición de metal, al menos de plomo para este periodo del Bajo Imperio. Los Cortes 4 y 5 demostraron una pérdida histórica reciente de la estratigrafía romana en todo el sector oriental del solar que, sin duda, nos hubiese podido aportar más datos sobre el proceso metalúrgico desarrollado en la ciudad en estos momentos. Sin embargo, no se han encontrado restos de hornos ni crisoles en la excavación, aunque la detección de parte de varias cisternas romanas, en un muro califal (U.E. 13) del Corte 2 , podría indicarnos la presencia de las correspondientes piletas de decantación del metal una vez fundido en el horno.

En cualquier caso, ésta es la primera vez que se documenta uno de los últimos procesos metalúrgicos, el de fundición, en la propia Colonia Patricia, cuando todas las evidencias, tanto históricas como arqueológicas, apuntan, para periodos republicanos y altoimperiales, a un procesado completo, tanto minero como metalúrgico, cercano a las mismas vetas y afloramientos metálicos, siendo el papel de la capital de la Baetica el de centro receptor de los lingotes y su transporte a través del Guadalquivir, para su distribución al resto del Imperio. Cuando se supone una decadencia de este sector económico (BALIL, 1965; BLÁZQUEZ, 1978: 242) e incluso un abandono total de las explotaciones para el N. de Córdoba, frente al apogeo durante la República y los inicios del Imperio, se constata la continuación de estos trabajos metalúrgicos en las postrimerías del siglo III d. C. e inicios del IV d. C.

\section{Conclusiones}

Los trabajos arqueológicos desarrollados en varios solares ubicados entre la Puerta del Puente y la Cruz del Rastro han proporcionado una serie de datos que nos ilustran sobre diversos aspectos de la vida de la ciudad durante la época imperial romana. Se han detectado dos ejes viarios de los que hasta ahora no se tenía constancia alguna, separados por una distancia que concuerda con las dimensiones establecidas para las insulae en esta zona de la ciudad. De estas calles lo que mejor ha podido documentarse han sido sus respectivos sistemas de drenaje, cuya tipología se ajusta a la conocida de época augustea, lo que unido a la inexistencia de estructuras de cronología republicana, corrobora la tesis de que la ampliación de la ciudad hasta el río tuvo lugar a partir del mandato de Augusto. Las excavaciones no han puesto al descubierto, como en un principio se esperaba, el lienzo fortificado meridional de la ciudad, pero todos los indicios apuntan a que éste debe localizarse inmediatamente al S., en la misma línea de fachada de Ronda de Isasa, o quizá, bajo la actual carretera. 
La documentación obtenida ha aportado además interesantes novedades sobre dos de los puntales en los que se basó la prosperidad económica y comercial de la urbe, el aceite de oliva y la minería. En el solar de la C/ Caño Quebrado, 3 debió desarrollarse una intensa actividad relacionada con la fabricación, almacenaje y posterior transporte de aceite, desde época augustea hasta s. III d.C., mientras que en Ronda de Isasa, 4 se ha constatado la práctica de labores metalúrgicas encaminadas a la obtención de plomo, a fines ya del s. III d.C. y comienzos de la siguiente centuria. Si tenemos en cuenta la proximidad de ambos solares entre sí, junto al río, no sería descabellado pensar que en esa zona hubiese existido un pequeño embarcadero desde donde se daría salida a los productos mencionados que serían comercializados a través de esa excepcional vía natural de comunicación que fue el Guadalquivir.

La práctica de estas actividades que, sin duda, debió ser molesta para la población al desarrollarse en el interior del perímetro amurallado, así como la ocupación y amortización de ciertos espacios públicos caso del kardo localizado en Ronda de Isasa, 4, evidencian algunos de los profundos cambios, que coincidentes con la construcción del palatium imperial de Cercadilla, modificarán de forma notable la imagen de la ciudad durante la tardoantiguiedad.

\section{BIBLIOGRAFÍA}

APARICIO, L. (1994): "Una réplica de Afrodita agachada en Córdoba". A.A.C., 5, 181-197.

BALIL, A. (1965): “Aspectos sociales del Bajo Imperio”. Latomus, 24, 886-892. BATERMAN, A.M. (1978): Yacimientos minerales de rendimiento económico. Madrid. BLANCO, A. (1962): "El aceite en los albores de la historia de España". Oretania, 10 , págs. $138-148$.

BLÁZQUEZ, J.Mª (1978): Historia económica de la Hispania romana. Madrid.

(1982-1983): "Noticia sobre las excavaciones arqueológicas en la mina republicana de La Loba (Fuente Obejuna, Córdoba)". Corduba Archaeologica, 12, 29-39.

BRUN, J.P. (1986): L'oléiculture antique en Provence. Les huileries du département $d u$ Var. Revue Archeologique de Narbonnaise. Suppl. 15. Paris.

CARRILLO, J.R. (1995): "Testimonios sobre la producción de aceite en época romana en la Subbética Cordobesa". Antiquitas, 6, págs. 53-91.

CASTEJÓN, R. (1964): “Nuevas identificaciones en la topografía de la Córdoba 
califal". Actas del I Congreso de Estüdios Arabes e Islámicos (Córdoba, 1962). Madrid, 373/389.

CHAVES, F. (1977): La Córdoba hispano-romana y sus monedas. Sevilla.

CHIC, G. (1988): Epigrafía anfórica de la Bética, II. Écija.

DOMERGUE, C. (1956): "Les lingots de plomb romains du Musée Archaeologique de Carthagène et du Musée Naval de Madrid". A.E.A., 39, 41-54.

_ (1972): "Rapports entre le zone minière de Sierra Morena et la plaine du Guadalquivir à l'époque romaine". M.C.V., 8. Madrid.

_(1987): Catalogue des mines et des fonderies antiques de la Péninsule Ibérique. 2 vol. Madrid.

_ (1989): Les mines de la Péninsule Ibérique dans l'Antiquité romaine. Roma.

DRACHMANN, A.G. (1932): Ancient Olive Mills and Presses. Copenhague.

ETIENNE, R. (1960): Le quartier nord-est de Volubilis. Paris.

IBAÑEZ, A. (1983): Córdoba hispano-romana. Córdoba.

KNAPP, R.C. (1983): Roman Córdoba. Berkeley-Los Ángeles-Londres.

LEON, P. (1996): "Hacia una nueva visión de la Córdoba romana". Colonia Patricia Corduba. Una reflexión arqueológica. (Coloquio Internacional. Córdoba, 1993). Córdoba, 17-35.

LOPEZ, A. (1981): Evolución urbana de Córdoba y de los pueblos campiñeses. Córdoba.

MARCOS, A y VICENT, A.Ma . (1985): "Investigación, técnicas, y problemas de las excavaciones en solares de la ciudad de Córdoba y algunos resultados topográficos generales". Arqueología de las ciudades modernas superpuestas a las antiguas (Zaragoza, 1983). Madrid, 233-252.

MARCOS, A; VICENT, A.M". y COSTA, J. (1977): "Trabajos arqueológicos en la ciudad de Córdoba, 1973". N.A.H., 5, 220-229.

MÁRQUEZ, E. (1983): “Fundiciones romanas de Sierra Morena”. B.R.A.C., 105, 223-234.

_ (1984): "Minería romana de Sierra Morena". B.R.A.C., 106, 173-200.

MELCHOR, E. (1993): "Vías romanas y explotación de los recursos mineros de la zona norte del Conventus Cordubensis". A.A.C., 4, 63-89. 
MONTEJO, A.J. y GARRIGUET, J.A. (1994): "El ángulo suroccidental de la muralla de Córdoba". A.A.C., 5, 243-276.

MORENA, J.A. (1997): “Apuntes sobre urbanismo y economía en el sector meridional de la Córdoba romana. Excavación arqueológica de urgencia en C/ Caño Quebrado esquina Ronda de Isasa". B.R.A.C., 132, 87-98.

MORENO, M. (1997): La villa altoimperial de Cercadilla (Córdoba). Análisis arqueológico. Sevilla.

PONSICH, M. (1980): "Nouvelles perspectives sur l'olivier du Bas-Guadalquivir dans l'antiquité". Producción y comercio del aceite en la Antigüedad. Primer Congreso Internacional. Madrid, págs. 47-56.

(1984): "Le facteur géographique dans les moyens de transport de l'huile de Bétique". Producción y comercio del aceite en la Antigüedad. Segundo Congreso Internacional. Madrid, págs. 102-113.

_ (1987): Implantation rurale antique sur le bas-Guadalquivir, III. Madrid.

PUCHOL, Ma .D. (1992): Urbanismo del Renacimiento en la ciudad de Córdoba. Córdoba.

RAMALLO, S.F. (1994): "Minería púnica y romana en el sureste peninsular: el foco de Carthago Nova". Minería y Metalurgia en la España Prerromana y Romana. Córdoba, 112-134.

RAMIREZ, T. (1995): Paseos por Córdoba, o sean apuntes para su Historia. Córdoba REMESAL, J. (1984): "Transformaciones en la exportación del aceite bético a mediados del s. III d.C.". Producción y comercio del aceite en la Antigüedad. Segundo Congreso Internacional. Madrid, págs. 116-131.

(1989): “Tres nuevos centros productores de ánforas Dressel 20 y 23. Los sellos de Lvcivs Fabivs Cilo". Ariadna, 6, págs. 121-153.

RODRIGUEZ ALMEIDA, E. (1980): "El monte Testaccio hoy: Nuevos testimonios epigráficos". Producción y comercio del aceite en la Antigüedad. Primer Congreso Internacional. Madrid, págs. 56-102.

_ (1989): Los tituli picti de las ánforas olearias béticas, I. Madrid.

RODRIGUEZ NEILA, J.F. (1988): Historia de Córdoba, I. Del amanecer prehistórico al ocaso visigodo. Córdoba.

SANTOS GENER, S. DE LOS (1955): Historia de Córdoba. Inédita. 
STYLOW, A. (1990): “Apuntes sobre el urbanismo de la Corduba romana". Stadbild und Ideologie. Die monumentalisierung hispanischer Städte zwischen Republik und Kaiserzeit (Madrid 1.987). Munich, 259-282.

VAQUERIZO, D; MURILLO, J.F; CARRILLO, J.R; MORENO, M.F; LEÓN, A; LUNA, Mª.D. y ZAMORANO, A.Ma . (1994): Arqueología Cordobesa. El Valle Alto del Guadiato (Fuenteobejuna, Córdoba). Córdoba.

VENY, C. (1969-1970): "Diecisiete lingotes de plomo de una nave romana de Las Salinas (Mallorca)". Ampurias, 31-32, 191-209

VENY, C. y CERDÁ, D. (1972): "Materiales arqueológicos de los pecios de la isla de Cabrera (Baleares)". T.P., 29, 299-305.

VENTURA. A. (1993): "Susum ad montes S(ocietatis) S(isaponensis): nueva inscripción tardorrepublicana de Corduba". A.A.C., 4, 49-61.

_ (1996): El abastecimiento de agua a la Córdoba romana, II. Acueductos, ciclo de distribución y urbanismo. Córdoba.

VENTURA, A; BERMUDEZ, J.M; LEON, P; LÓPEZ, I; MARQUEZ, C. y VENTURA, J.J. (1996): "Análisis arqueológico de la Córdoba romana: Resultados e hipótesis de la investigación”. Colonia Patricia Corduba. Una reflexión arqueológica. (Coloquio Internacional. Córdoba, 1993). Córdoba, 87-118. 


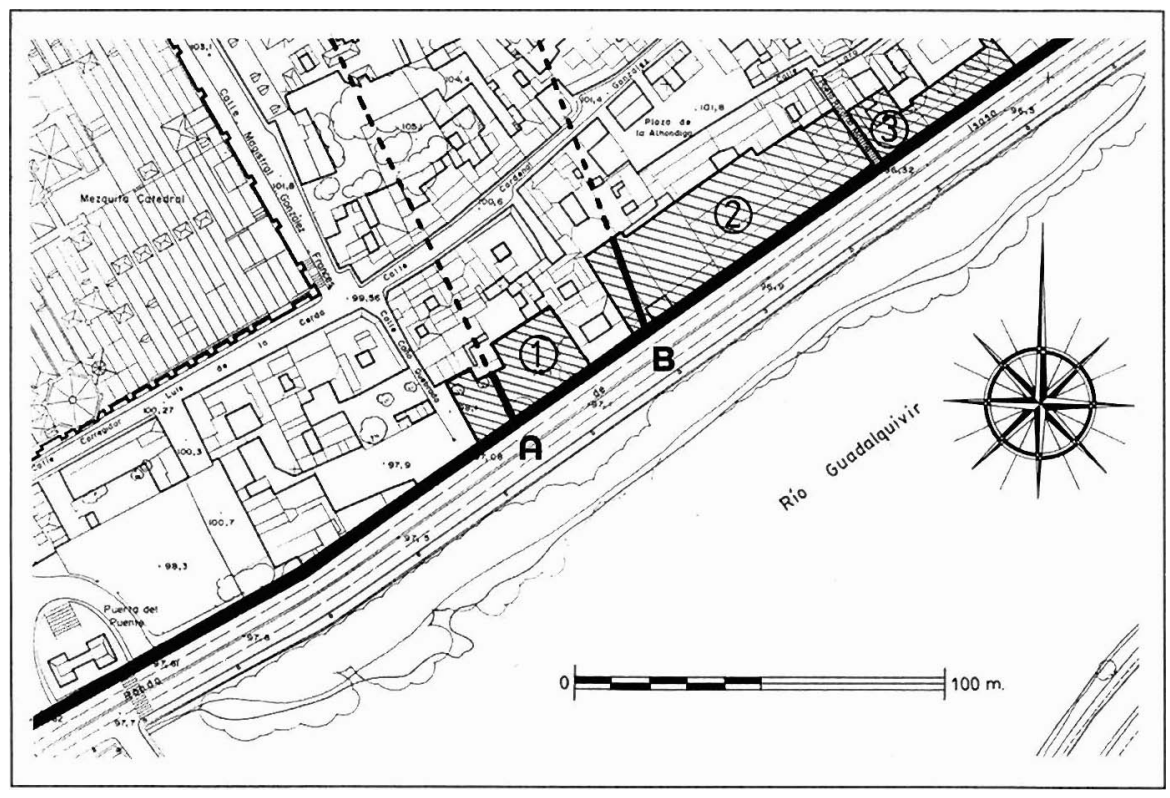

Fig. 1: Localización de los solares excavados en el sector de la Ribera. Hoja 923 (1-3) $10 / 10$.

Fig. 2: Ubicación de los cardines detectados en C/ Caño Quebrado, 3 y Ronda de Isasa, 4 dentro de la trama urbana de Córdoba en época romana (según Márquez et alii, 1996)

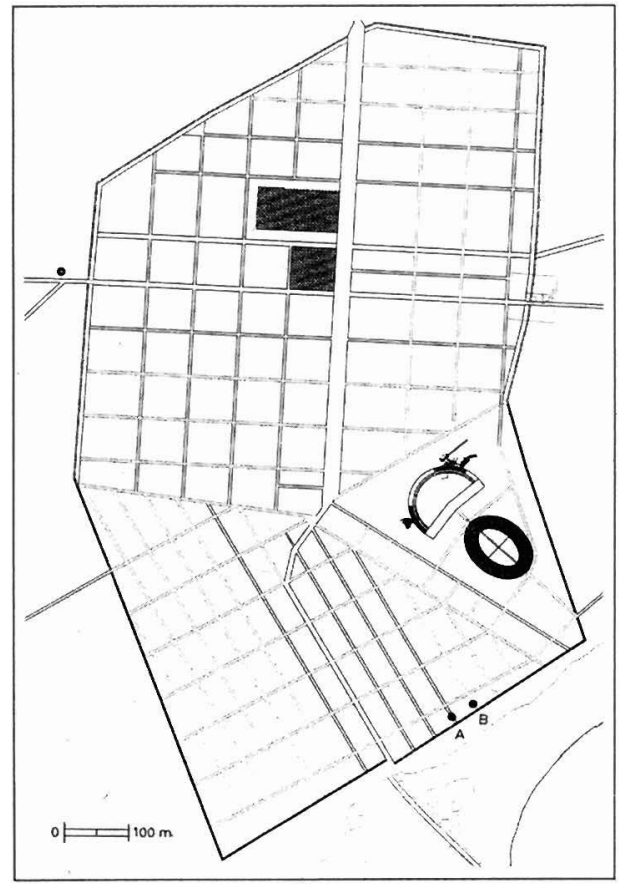




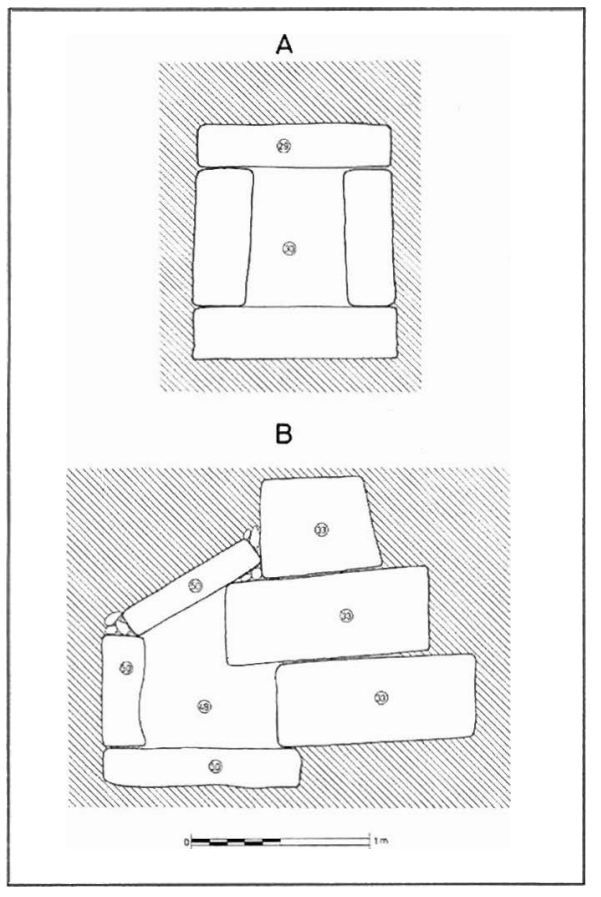

Fig. 3: Secciones de las cloacas documentadas en C/ Caño Quebrado, 3 (A) y Ronda de Isasa, 4 (B).

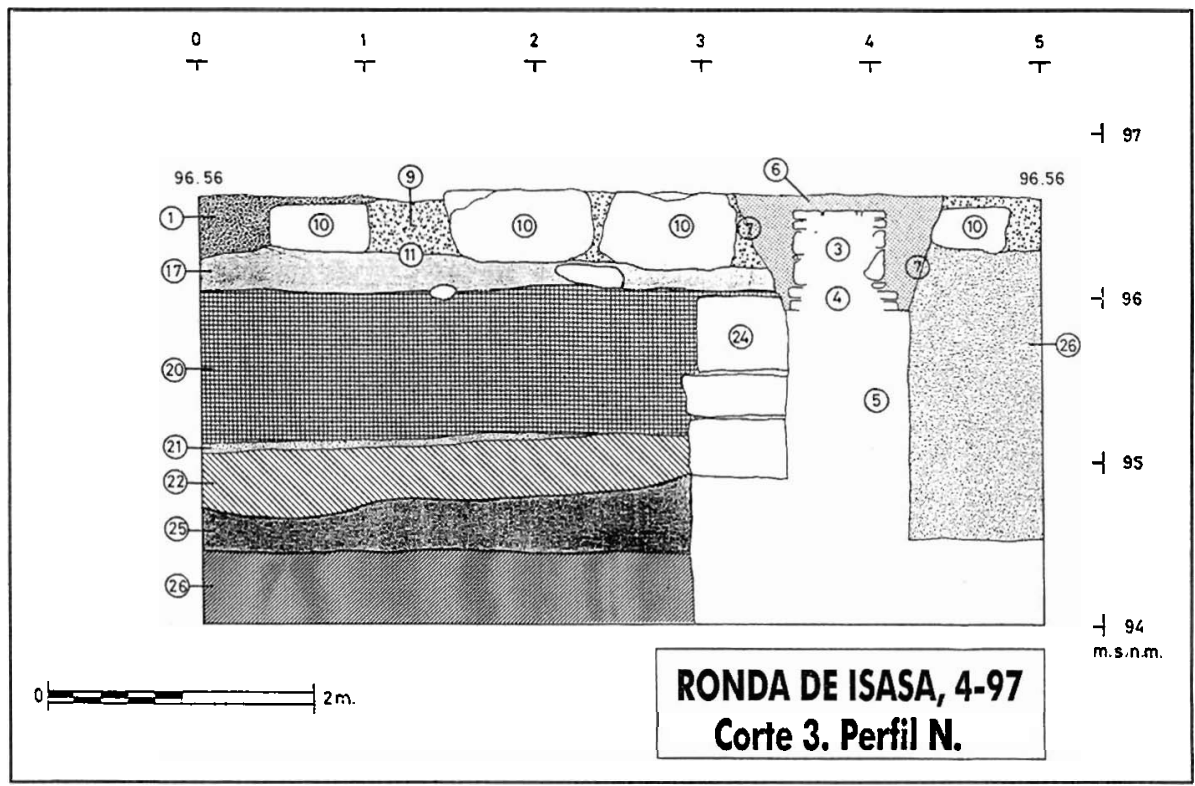

Fig. 4: Perfil N. del Corte 3. Ronda de Isasa, 4-97. 


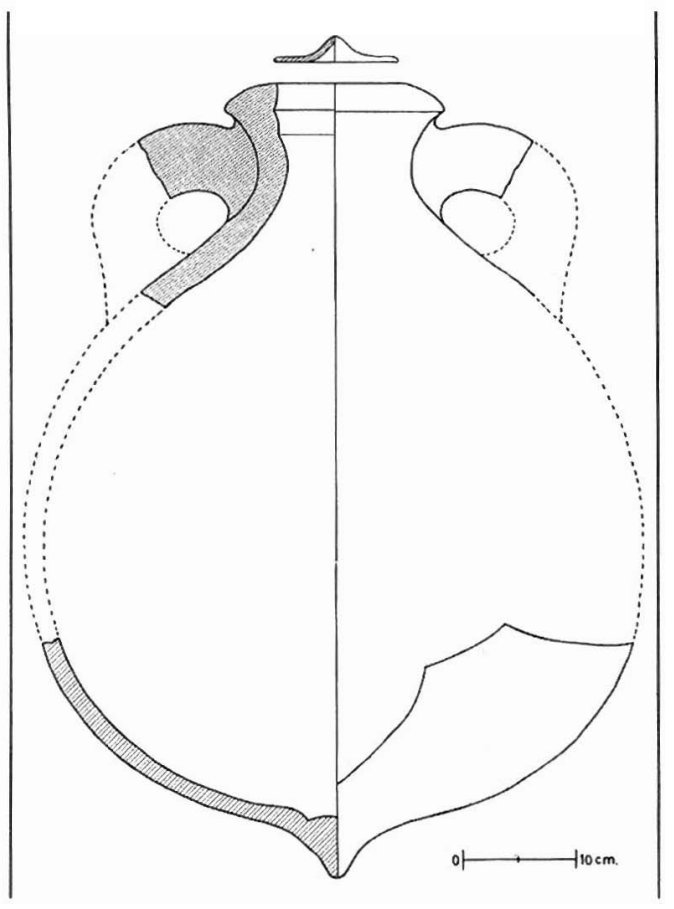

Fig. 5: Tapadera y ánfora olearia bética tipo Dressel 20. Corte 3. C/ Caño Quebrado, 3-95.
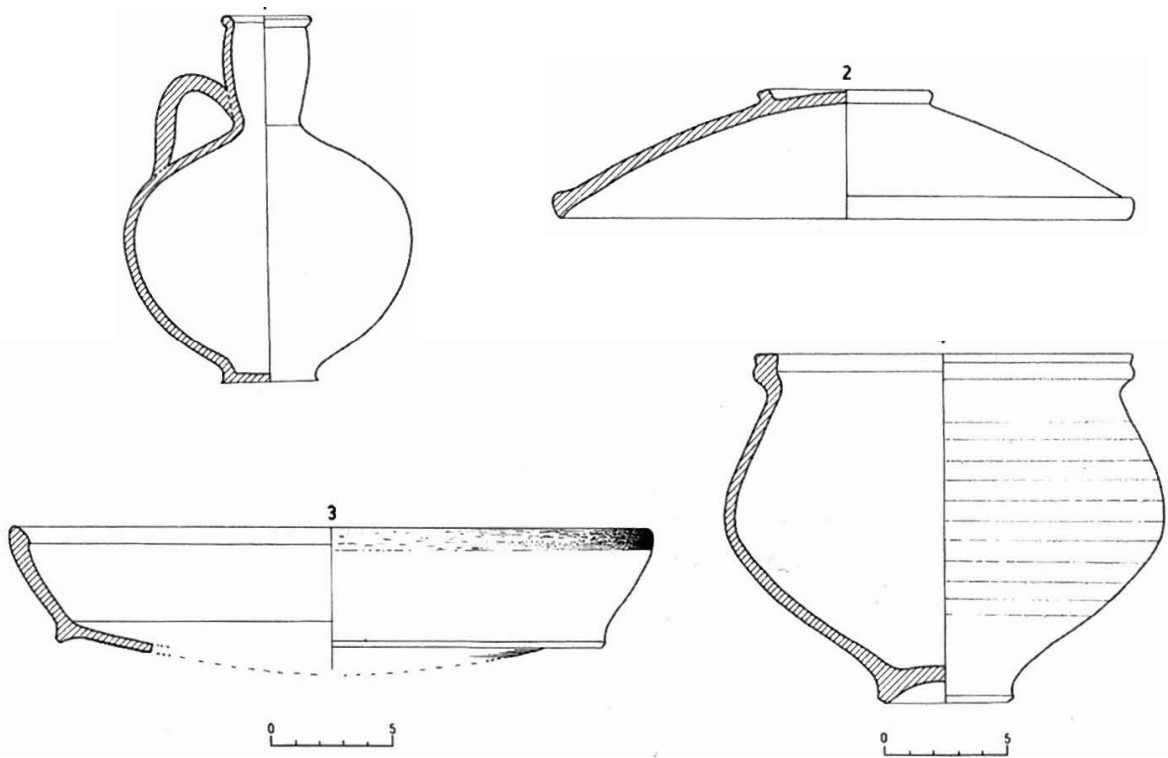

Fig. 6: Cerámicas romanas comunes y africanas de cocina del Corte 4. C/ Caño Quebrado, 3-95. 


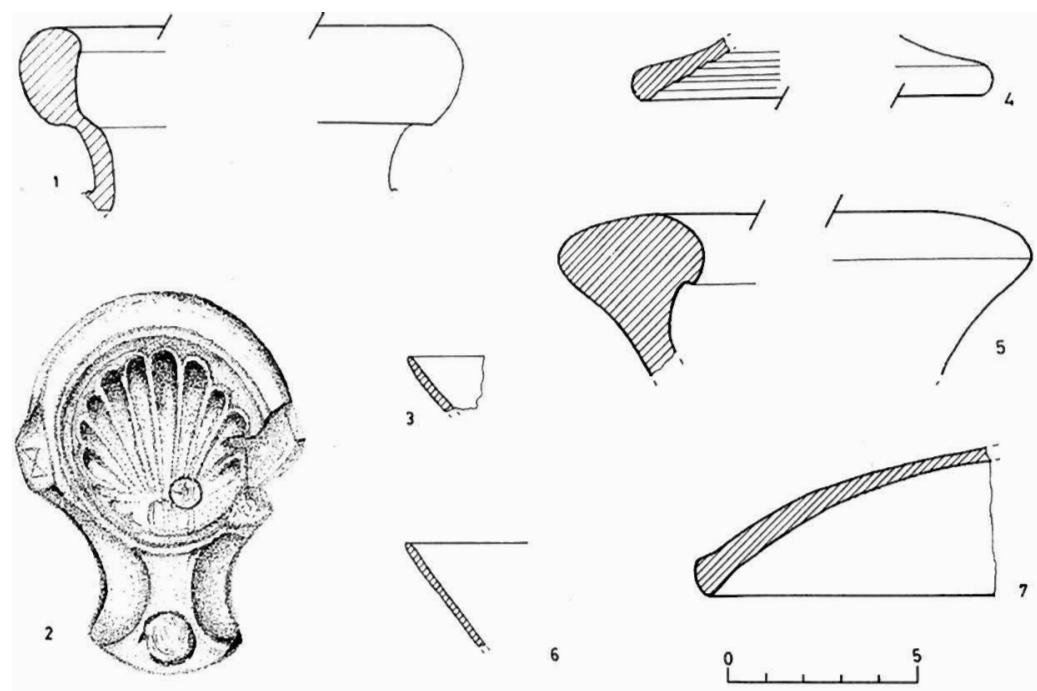

Fig. 7: Cerámicas romanas comunes, africanas y borde de ánfora olearia del Corte 3. Ronda de Isasa. 4-97.

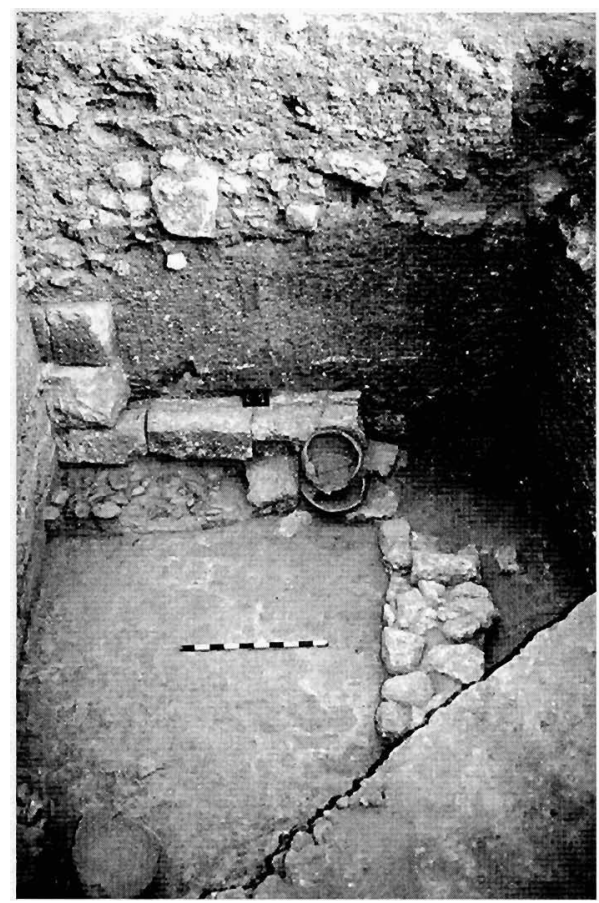

Lám. I: Vista parcial del Corte 1. C/ Caño Quebrado, 3-95. 


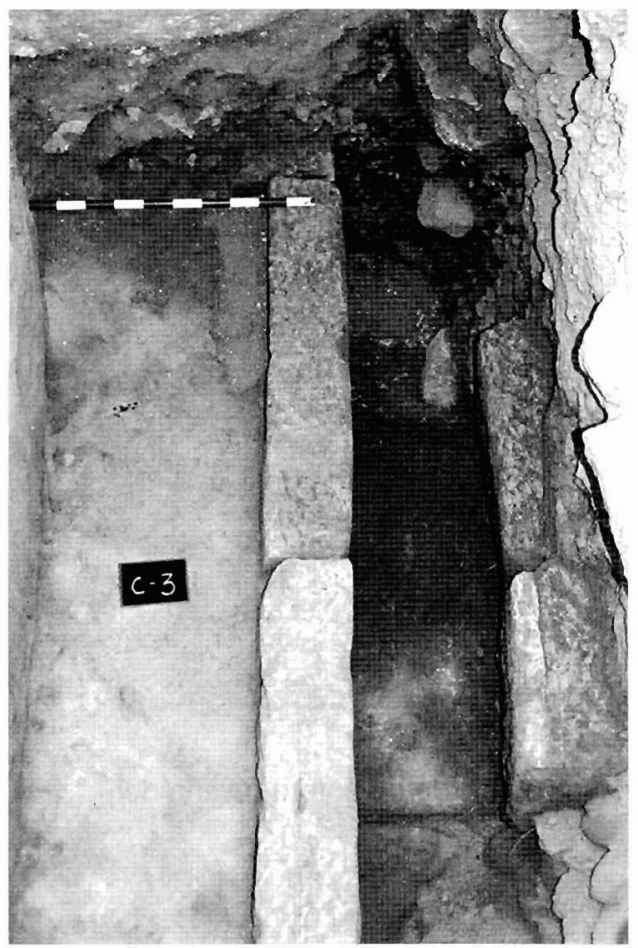

Lám. II: Detalle de la cloaca hallada en el Corte 3. C/ Caño Quebrado. 3-95.

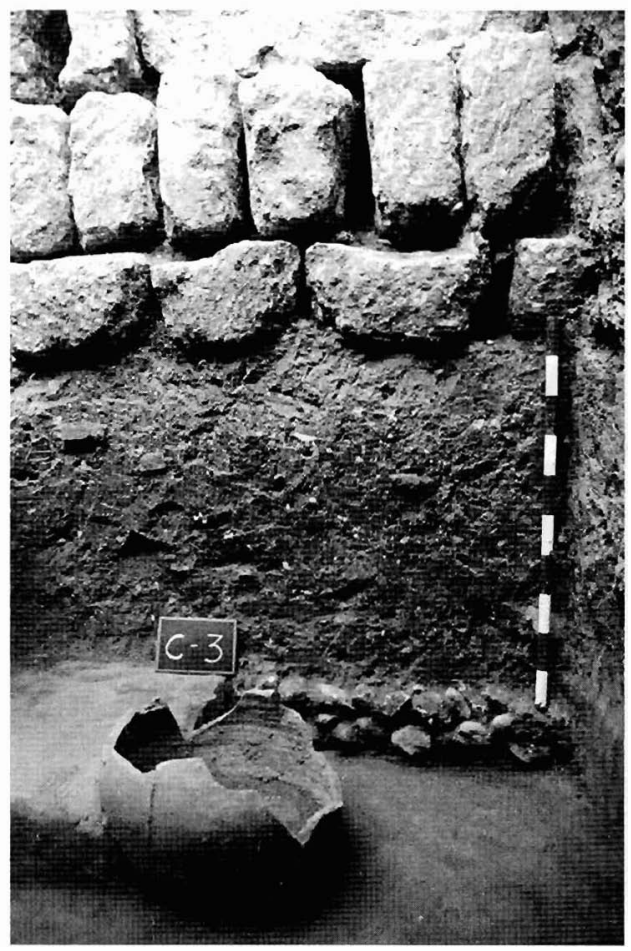



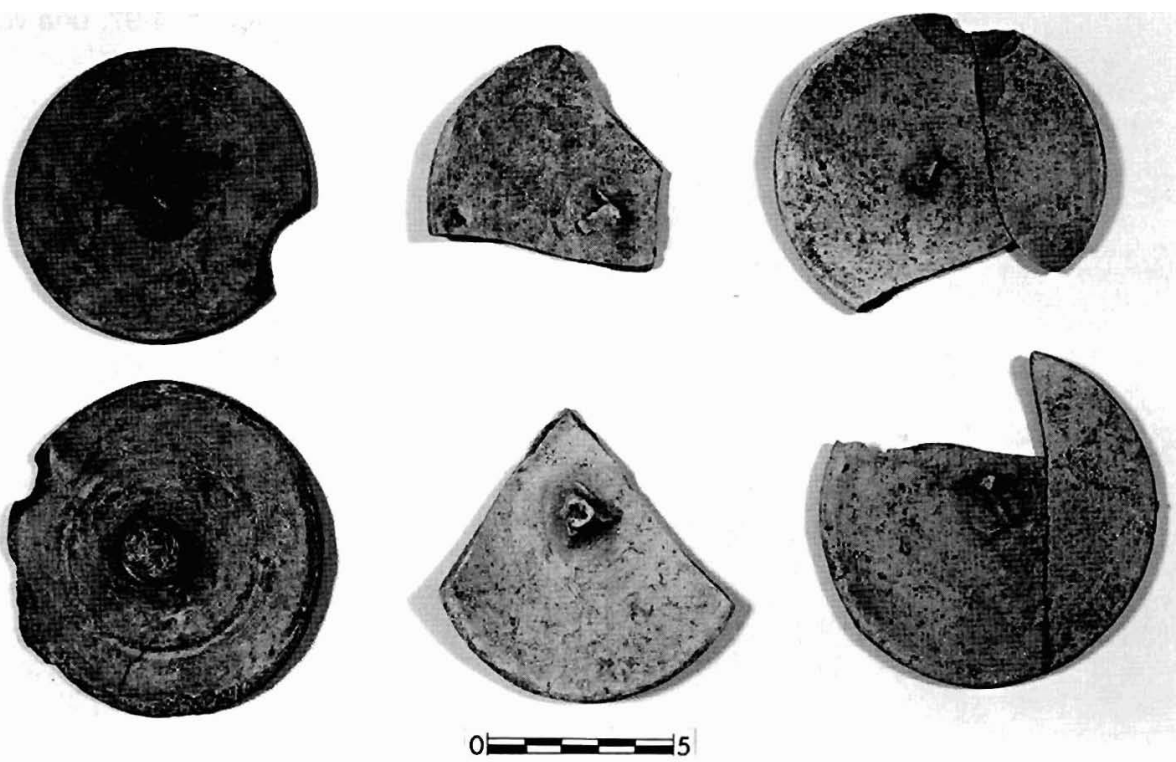

Lám. IV: Tapaderas de ánforas olearias halladas en C/ Caño Quebrado, 3-95

Lám. V: Detalle de la estructura de sillares U.E. 33 y de la cubierta de la cloaca U.E. 50 del Corte 1. Ronda de Isasa, 4-97.

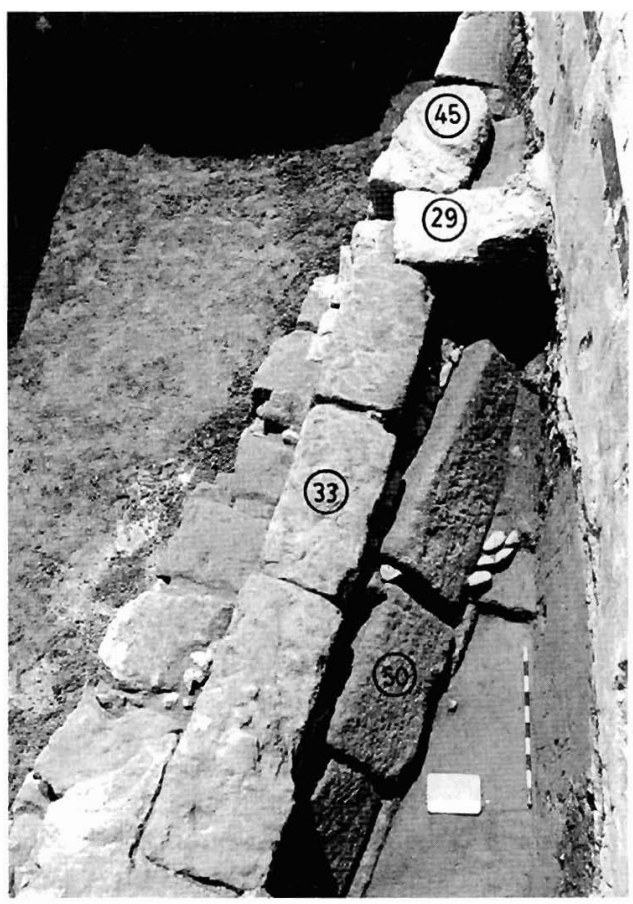




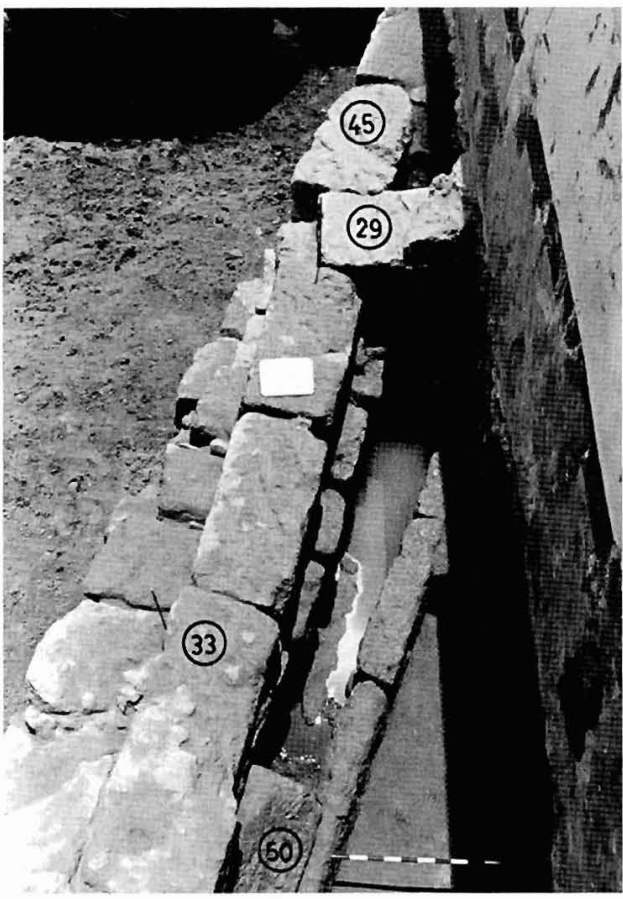

Lám. VI: Otro momento de la excavación de la cloaca de Ronda de Isasa, 4-97, una vez levantadas las losas de la cubierta

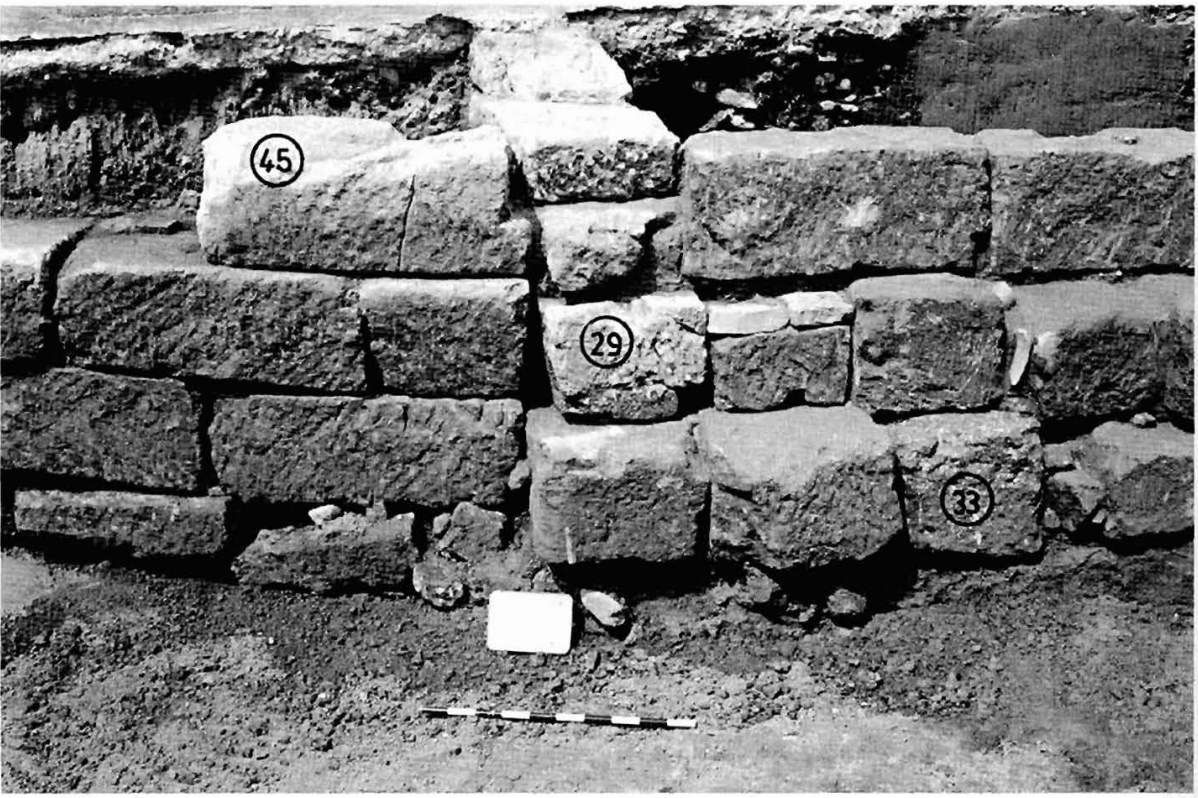

Lám. VII: Detalle del muro oriental U.E. 45 del kardo y de los muros con sillares reparovechados UU.EE. 29 y 33 en el Corte 1 de Ronda de Isasa, 4-97 


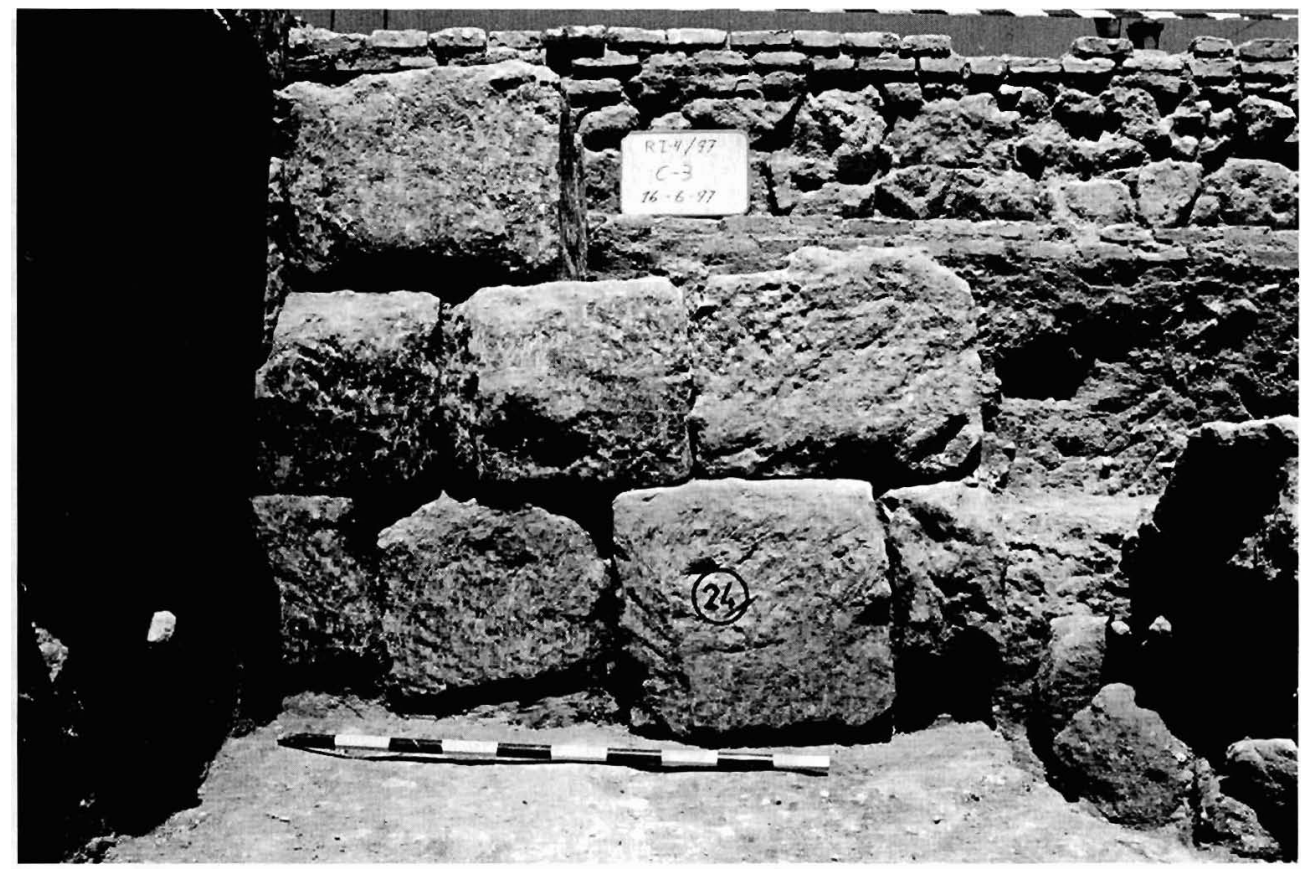

Lám. VIII: Alzado del muro de sillares U.E. 24 del Corte 3. Ronda de Isasa, 4-97 


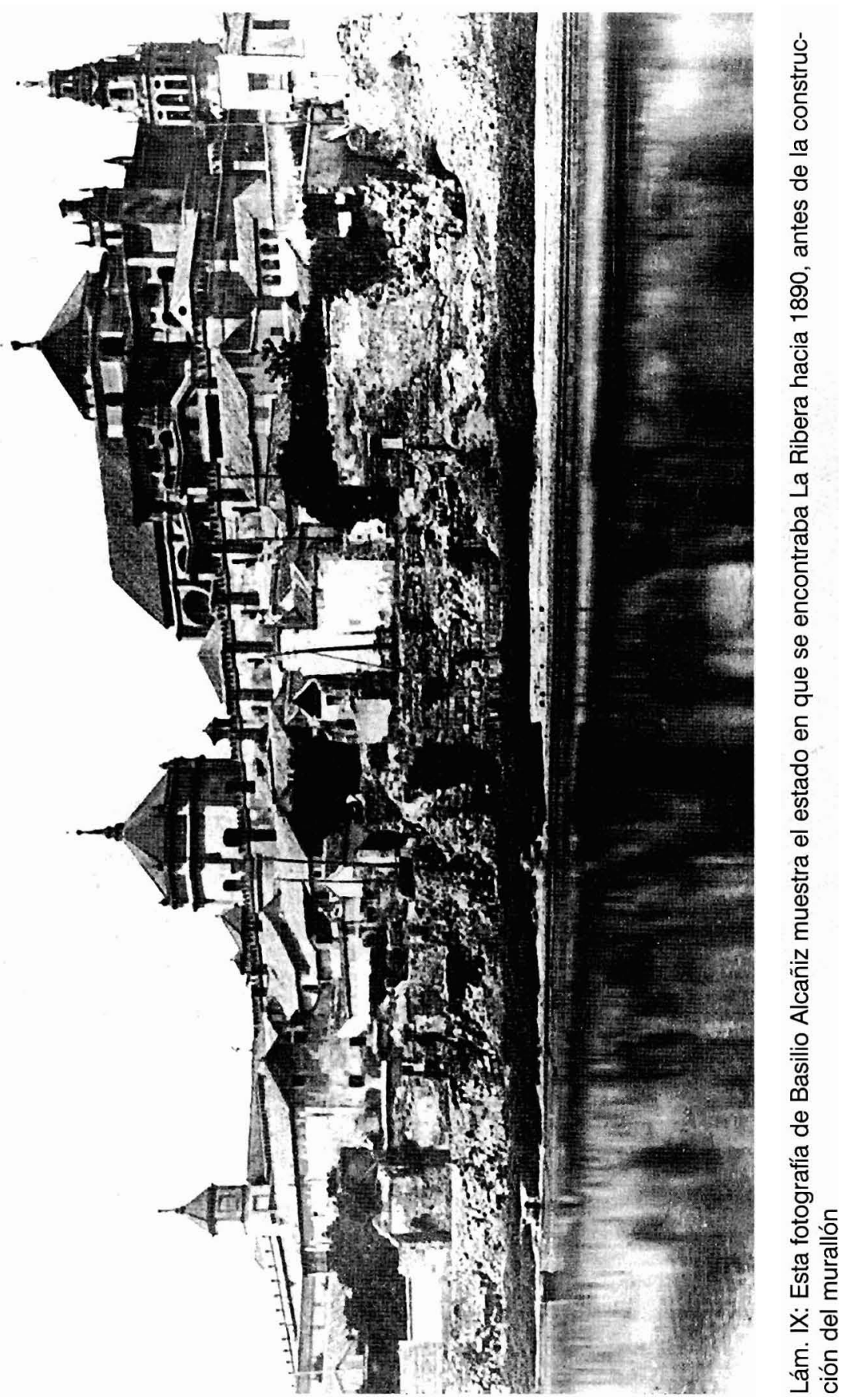

